\title{
PAPER
}

Cite this: Phys. Chem. Chem. Phys., 2013, 15, 8529

Received 30th November 2012 Accepted 6th March 2013

DOI: $10.1039 / \mathrm{c} 3 \mathrm{cp} 44298 \mathrm{e}$

www.rsc.org/pccp

\section{Effects of rare-earth co-doping on the local structure of rare-earth phosphate glasses using high and low energy X-ray diffraction}

\author{
Alisha J. Cramer, ${ }^{\text {ab }}$ Jacqueline M. Cole, ${ }^{\text {abc }}$ Vicky FitzGerald, ${ }^{d}$ Veijo Honkimaki, ${ }^{e}$ \\ Mark A. Roberts, ${ }^{\dagger}$ Tessa Brennan, ${ }^{9}$ Richard A. Martin, $\dagger^{9}$ George A. Saunders ${ }^{9}$ and \\ Robert J. Newport ${ }^{d}$
}

\begin{abstract}
Rare-earth co-doping in inorganic materials has a long-held tradition of facilitating highly desirable optoelectronic properties for their application to the laser industry. This study concentrates specifically on rare-earth phosphate glasses, $\left(\mathrm{R}_{2} \mathrm{O}_{3}\right)_{x}\left(\mathrm{R}_{2}^{\prime} \mathrm{O}_{3}\right)_{y}\left(\mathrm{P}_{2} \mathrm{O}_{5}\right)_{1-(x+y)}$, where $\left(\mathrm{R}, \mathrm{R}^{\prime}\right)$ denotes $(\mathrm{Ce}, \mathrm{Er})$ or $(\mathrm{La}, \mathrm{Nd})$ co-doping and the total rare-earth composition corresponds to a range between metaphosphate, $\mathrm{RP}_{3} \mathrm{O}_{9}$, and ultraphosphate, $\mathrm{RP}_{5} \mathrm{O}_{14}$. Thereupon, the effects of rare-earth co-doping on the local structure are assessed at the atomic level. Pair-distribution function analysis of high-energy $\mathrm{X}$-ray diffraction data $\left(Q_{\max }=28 \AA^{-1}\right)$ is employed to make this assessment. Results reveal a stark structural invariance to rare-earth co-doping which bears testament to the open-framework and rigid nature of these glasses. A range of desirable attributes of these glasses unfold from this finding; in particular, a structural simplicity that will enable facile molecular engineering of rare-earth phosphate glasses with 'dial-up' lasing properties. When considered together with other factors, this finding also demonstrates additional prospects for these co-doped rare-earth phosphate glasses in nuclear waste storage applications. This study also reveals, for the first time, the ability to distinguish between $\mathrm{P}-\mathrm{O}$ and $\mathrm{P}=\mathrm{O}$ bonding in these rare-earth phosphate glasses from X-ray diffraction data in a fully quantitative manner. Complementary analysis of high-energy $\mathrm{X}$-ray diffraction data on single rare-earth phosphate glasses of similar rare-earth composition to the co-doped materials is also presented in this context. In a technical sense, all high-energy X-ray diffraction data on these glasses are compared with analogous low-energy diffraction data; their salient differences reveal distinct advantages of high-energy $\mathrm{X}$-ray diffraction data for the study of amorphous materials.
\end{abstract}

\section{Introduction}

For many years, rare-earth (R) phosphate glasses with compositions and local structures similar to those of metaphosphate,

\footnotetext{
${ }^{a}$ Cavendish Laboratory, University of Cambridge, J.J. Thomson Avenue, Cambridge, CB3 OHE, UK. E-mail: jmc61@cam.ac.uk

${ }^{b}$ Department of Physics, University of New Brunswick, P.O. Box 4400, Fredericton, E3B 5A3, Canada

${ }^{c}$ Department of Chemistry, University of New Brunswick, P.O. Box 4400, Fredericton, E3B 5A3, Canada

${ }^{d}$ School of Physical Sciences, University of Kent, Canterbury, Kent CT2 7NR, UK

${ }^{e}$ European Synchrotron Radiation Facility, B. P. 220, Grenoble Cedex 9, France

${ }^{f}$ Synchrotron Radiation Source, Daresbury Laboratory, Warrington, Cheshire, WA4 $4 A D, U K$

${ }^{g}$ Department of Physics, University of Bath, Claverton Down, Bath, BA2 7AY, UK $\dagger$ Current address: School of Engineering \& Aston Research Centre for Healthy Ageing, University of Aston, Birmingham, B4 7ET, UK.
}

$\mathrm{R}\left(\mathrm{PO}_{3}\right)_{3}$, and ultraphosphate, $\mathrm{RP}_{5} \mathrm{O}_{14}$, have been subject to continued interest for their high potential for the laser and optoelectronics industry. ${ }^{1-6}$ In the laser industry, in particular, successful solid-state lasers using neodymium, erbium, or co-doped $(\mathrm{Er}, \mathrm{Yb})$ glass have been created and used for some time, ${ }^{7-9}$ using glass of composition $\operatorname{LiEr}_{x} \mathrm{Yb}_{y} \mathrm{La}_{(1-x-y)} \mathrm{P}_{4} \mathrm{O}_{12}$. Furthermore, Zhang et $a .^{7}$ reported that lasing performance was much stronger in the co-doped glass than in glass doped with erbium alone. More recently, Martin and Knight ${ }^{10}$ demonstrated that silica-clad optical fibres using co-doped (La, Nd) phosphate glass cores could be fabricated, and made to lase successfully. Given the inherent relationship between the local structure and its optoelectronic properties, the local structure of rare-earth phosphate glasses has been studied in some detail. ${ }^{11-26}$ However, these studies have focused on glasses containing only one rare-earth type; the effect of 
co-doping on the local structure would therefore be of substantial interest.

The structural characteristics of $\left(\mathrm{R}_{2} \mathrm{O}_{3}\right)_{x}\left(\mathrm{P}_{2} \mathrm{O}_{5}\right)_{1-x}$ glasses containing a single rare-earth type have been probed extensively as a function of varying rare-earth ions and different rareearth concentrations. ${ }^{11-18}$ The nature of the nearest-neighbour $\mathrm{R} \cdot \mathrm{R}$ separation has also garnered much attention owing to the recognition that the closest approach between rare-earth ions has a large effect on the physical properties of the glass: if the $\mathrm{R}^{3+}$ ions are too close together, the optical and magnetic properties of the glass become impeded.

Specifically, a number of complementary X-ray and neutron diffraction, and extended X-ray absorption fine structure (EXAFS), studies have been undertaken by Cole et al., ${ }^{13}$ Cole et al. ${ }^{14}$ Cole et al.,${ }^{15}$ Hoppe et al., ${ }^{16}$ and Anderson et al. ${ }^{19}$ in order to investigate the effect of the lanthanide contraction on $\left(\mathrm{R}_{2} \mathrm{O}_{3}\right)_{x}\left(\mathrm{P}_{2} \mathrm{O}_{5}\right)_{1-x}$ glasses with increasing rare-earth atomic number, from La to $\mathrm{Yb}$. The motivation behind this enquiry was the idea that there might be significant structural variation in the immediate rare-earth environment, which might then filter into the phosphate network as well. The results indicated a trend of decreasing $\mathrm{R}^{3+}$ coordination number with increasing rare-earth atomic number, ${ }^{14}$ and the interatomic $\mathrm{R}-\mathrm{O}$ distances reproduced the lanthanide contraction, as expected. ${ }^{11-15}$ The immediate rare-earth environment therefore depends on ionic size; ${ }^{11}$ results also evidenced rare-earth clustering in glasses with seven-coordinate $\mathrm{R}^{3+}$ environments where compositions were close to the metaphosphate limit. ${ }^{18}$ No evidence of significant changes to the corresponding phosphate network has been found. ${ }^{11-18}$

Meanwhile, the closest $\mathrm{R} \cdots \mathrm{R}$ separation was probed by anomalous dispersion neutron diffraction $(\mathrm{R}=\mathrm{Sm}, x=0.205),{ }^{27}$ and a magnetic difference neutron diffraction experiment $(\mathrm{R}=\mathrm{Tb}, x=0.246),{ }^{28}$ revealing minimum $\mathrm{R} \cdots \mathrm{R}$ distances of $\sim 4$ and $3.9 \AA$ A, respectively.

This study focuses on the structural perturbations caused by incorporating a mixture of rare-earths into these glasses. With such an extensive structural knowledge base on $\left(\mathrm{R}_{2} \mathrm{O}_{3}\right)_{x}\left(\mathrm{P}_{2} \mathrm{O}_{5}\right)_{1-x}$ glasses in hand, where $\mathrm{R}$ is a single rare-earth, this study is particularly well primed. Specifically, two series of co-doped rareearth phosphate glasses, $\left(\mathrm{R}_{2} \mathrm{O}_{3}\right)_{x}\left(\mathrm{R}_{2}^{\prime} \mathrm{O}_{3}\right)_{y}\left(\mathrm{P}_{2} \mathrm{O}_{5}\right)_{1-(x+y)}$ are presented, where $\mathrm{R}$ and $\mathrm{R}^{\prime}$ represent two different rare-earths, according to $\left(\mathrm{R}, \mathrm{R}^{\prime}\right)=(\mathrm{Ce}, \mathrm{Er})$ with $x=0.047-0.178$ and $y=0.043-0.190$, and $\left(\mathrm{R}, \mathrm{R}^{\prime}\right)=(\mathrm{La}, \mathrm{Nd})$ with $x=0.147-0.260$ and $y=0.010-0.099$. Results are compared with those from the single rare-earth phosphate glasses. Features of particular interest are associated with the effects of varying the ratio of the rare-earth concentration, $x: y$, with emphasis on how the glass structure adjusts on moving from a glass that is dominated by a higher atomic number (smaller ionic radius) to one of lower atomic number (larger ionic radius). We also investigate the effects of structural resolution on the data interpretation, comparing results of the (Ce, Er) data taken from high and low energy synchrotron generated X-rays. For reference, an analogous comparative investigation was performed on the series of single rare-earth phosphates $\left(\mathrm{R}_{2} \mathrm{O}_{3}\right)_{x}\left(\mathrm{P}_{2} \mathrm{O}_{5}\right)_{1-x}, \mathrm{R}=\mathrm{La}, \mathrm{Ce}$, Pr, Sm, Gd, Tb, and Er.

\section{Experimental}

\section{Sample preparation}

All samples of both single and mixed rare-earth compositions were prepared following the method described by Mierzejewski et $a .^{29}$ This essentially involved heating a 1:4 ratio of high purity (99.9\%) rare-earth oxide and $\mathrm{P}_{2} \mathrm{O}_{5}$ in an aluminium oxide crucible at a temperature corresponding to the appropriate rare-earth oxide melt (1400-1650 ${ }^{\circ} \mathrm{C}$ ), followed by annealing. All raw chemicals were obtained from Sigma Aldrich and used without further purification. The sample composition was determined by electron probe microanalysis whilst the bulk density measurements used the Archimedes principle via a measure of the weight of the sample in both air and water; ${ }^{30}$ the results are shown in Table 1. A small amount of $\mathrm{Al}_{2} \mathrm{O}_{3}(1-2 \mathrm{wt} \% \mathrm{Al})$ contaminates the samples, arising from the crucible used in sample preparation; this is regularly detected in conventional X-ray and neutron diffraction experiments. ${ }^{15,16}$ The contaminant is, however, extremely useful from a materialscentred perspective since it prevents the material from becoming brittle. $^{15}$

\section{X-ray diffraction experiments}

All of the presented samples underwent X-ray diffraction at the high energy beamline ID15 at the European Synchrotron Radiation Facility (ESRF) in Grenoble, France. Samples were finely powdered and encapsulated inside a $1 \mathrm{~mm}$ thick circular metal annulus by Kapton windows and mounted onto a flatplate instrumental set-up which houses a MAR345 image plate detector. Incident photons with $\lambda=0.1328 \AA(E=93.52 \mathrm{keV})$ were used with a $0.5 \times 0.5 \mathrm{~mm}$ square beam cross-section. Data for each compound were acquired in six sets: one each at a sample-detector distance of $550 \mathrm{~mm}\left(2 \theta=0.02-18^{\circ}\right)$ and $300 \mathrm{~mm}\left(2 \theta=0.03-31^{\circ}\right)$, and four sets at a sample-detector distance of $170 \mathrm{~mm}\left(2 \theta=0.05-45^{\circ}\right)$. The data covered a total range of $Q=0.013-37 \AA^{-1}$, although the usable dynamic range after data reduction was $Q=0.43-28 \AA^{-1}$.

The mixed (Ce, Er) composition samples also underwent X-ray diffraction at Station 9.1 of the Synchrotron Radiation Source (SRS), Daresbury Laboratory, in the UK. The samples were finely powdered and encapsulated inside a $0.5 \mathrm{~mm}$ thick circular metal annulus by Kapton windows and mounted onto a

Table 1 The compositions and densities of the co-doped rare-earth phosphate glasses, $\left(\mathrm{R}_{2} \mathrm{O}_{3}\right)_{x}\left(\mathrm{R}_{2}^{\prime} \mathrm{O}_{3}\right)_{y}\left(\mathrm{P}_{2} \mathrm{O}_{5}\right)_{1-(x+y)}$, and the singly-doped glasses, $\left(\mathrm{R}_{2} \mathrm{O}_{3}\right)_{x}\left(\mathrm{P}_{2} \mathrm{O}_{5}\right)_{1-x}$, used in this study. All of the glasses also contain trace (1-2 wt\%) amounts of aluminium

\begin{tabular}{|c|c|c|c|c|c|c|c|}
\hline \multicolumn{5}{|c|}{ Co-doped glasses } & \multicolumn{3}{|c|}{ Singly-doped glasses } \\
\hline $\mathrm{R}$ & $\mathrm{R}^{\prime}$ & $x[ \pm 0.005]$ & $y[ \pm 0.005]$ & $\rho\left(\mathrm{g} \mathrm{cm}^{-3}\right)$ & $\mathrm{R}$ & $x[ \pm 0.005]$ & $\rho\left(\mathrm{g} \mathrm{cm}^{-3}\right)$ \\
\hline $\mathrm{Ce}$ & $\mathrm{Er}$ & 0.047 & 0.190 & 3.472 & $\mathrm{La}$ & 0.225 & 3.199 \\
\hline $\mathrm{Ce}$ & $\mathrm{Er}$ & 0.091 & 0.132 & 3.435 & $\mathrm{Ce}$ & 0.197 & 3.251 \\
\hline $\mathrm{Ce}$ & $\mathrm{Er}$ & 0.111 & 0.108 & 3.373 & $\mathrm{Pr}$ & 0.239 & 3.310 \\
\hline $\mathrm{Ce}$ & $\mathrm{Er}$ & 0.178 & 0.043 & 3.326 & $\mathrm{Sm}$ & 0.169 & 3.160 \\
\hline $\mathrm{La}$ & $\mathrm{Nd}$ & 0.147 & 0.099 & 3.257 & $\mathrm{Sm}$ & 0.205 & 3.199 \\
\hline $\mathrm{La}$ & $\mathrm{Nd}$ & 0.190 & 0.043 & 3.167 & Gd & 0.232 & 3.409 \\
\hline $\mathrm{La}$ & $\mathrm{Nd}$ & 0.226 & 0.019 & 3.155 & $\mathrm{~Tb}$ & 0.263 & 3.53 \\
\hline $\mathrm{La}$ & $\mathrm{Nd}$ & 0.260 & 0.010 & 3.294 & $\mathrm{Er}$ & 0.239 & 3.480 \\
\hline
\end{tabular}


flat-plate that operates a rotational stage to average out any preferred orientation effects. Data were acquired on a 1-D serial-counter detector at room temperature in increments of $0.2^{\circ}$ using $2 \theta-\omega$ bisecting geometry, covering a $2 \theta$ range of $1.6-126^{\circ}\left(Q=0.36-23 \AA^{-1}\right)$, with a wavelength of $\lambda=0.486 \AA$ $(E=25.56 \mathrm{keV})$ and beam cross-section of $9.0 \times 0.86 \mathrm{~mm}$.

\section{Data analysis}

General data analysis is based upon Warren. ${ }^{31}$ ESRF data were first merged and normalized, and corrections for background, beam polarization, and absorption were applied to the experimental data. This involved scaling and fitting the data to the sum of the theoretical values for Compton ${ }^{32,33}$ and atomic ${ }^{34}$ scattering as a function of $2 \theta$, using an iterative method. An example of the fit of the intensity profile to the theoretical scattering profile is given in Fig. 1 for the $\left(\mathrm{Ce}_{2} \mathrm{O}_{3}\right)_{0.178}\left(\mathrm{Er}_{2} \mathrm{O}_{3}\right)_{0.043}\left(\mathrm{P}_{2} \mathrm{O}_{5}\right)_{0.779}$ sample, measured at the (a) ESRF; (b) SRS. The interference function, $i(Q)$, was calculated via

$$
i(Q)=\frac{I_{\exp }-\left(\left\langle f^{2}\right\rangle+I_{\mathrm{c}}\right)}{\langle f\rangle^{2} \bar{z}^{2}}
$$

where $Q$ is the magnitude of the scattering vector, $I_{\exp }$ is the corrected and scaled experimental intensity, $I_{\mathrm{c}}$ is the sum of the relative Compton normalized contributions for each atom type, $\left\langle f^{2}\right\rangle$ is the sum of the relative contributions for each atom type of the square of the self-scattering factors, $\langle f\rangle^{2}$ is the square of the sum of the relative contributions of the self-scattering factors for each atom type (often called the sharpening function), and $\bar{z}^{2}$ is the mean number of electrons in a scattering unit.

A smoothing function within a small $\left(\Delta Q \sim 2.4 \AA^{-1}\right)$ region at a position $Q \approx 23.5 \AA^{-1}$ was applied to all ESRF data in order to merge data for the $300 \mathrm{~mm}$ and $170 \mathrm{~mm}$ sample-to-detector distances; analysis of the corresponding forward and backward
Fourier transforms ensured that this merging imparted no observable changes to the structural profile.

Evaluation of the atomic pairwise distribution function (PDF) was carried out using the Fourier transform,

$$
t(r)=2 \pi^{2} r \rho_{0}+\int_{Q_{\min }}^{Q_{\max }} M Q i(Q) \sin (Q r) \mathrm{d} Q,
$$

where $r$ is the separation between two given pairs of atoms, $\rho_{0}$ is the atomic density, and $M$ is a Hanning window function that suppresses Fourier transform termination effects according to $M=\left(1+\cos \left(\pi Q / Q_{\max }\right)\right) / 2$. Each atomic correlation was modelled by fitting a reciprocal space version of a Gaussian using an approach by Gaskell ${ }^{35}$

$$
p_{i j}(Q)=N_{i j}\left(\frac{w_{i j}}{c_{j}}\right)\left(\frac{\sin \left(Q R_{i j}\right)}{Q R_{i j}}\right)\left(\exp \left(\frac{-Q^{2} \sigma_{i j}^{2}}{2}\right)\right) .
$$

Here, $N_{i j}, R_{i j}$, and $\sigma_{i j}{ }^{2}$ are the coordination number, atomic separation, and Debye-Waller factors of atom $i$ with respect to atom $j$ respectively; $c_{j}$ is the composition fraction of atom $j$; and $w_{i j}$ is a weighting function of atoms $i$ and $j$. The latter follows the relation

$$
\begin{gathered}
w_{i j}=\frac{2 c_{i} f_{i}(Q) c_{j} f_{j}(Q)}{\overline{f(Q)^{2}}} \text { where } i \neq j \\
w_{i j}=\frac{\left(c_{i} f_{i}(Q)\right)^{2}}{\overline{f(Q)^{2}}} \quad \text { where } i=j .
\end{gathered}
$$

Initial fitting values of $N_{i j}, R_{i j}$ and $\sigma_{i j}{ }^{2}$ were taken from those obtained for single rare-earth phosphate glasses. ${ }^{14}$ Refinement of the $N_{i j}, R_{i j}$ and $\sigma_{i j}^{2}$ parameters was undertaken iteratively in $Q$-space, with recursive conversions of $i(Q)$ into $t(r)$ for checking the quality of the fit of the sum of the pair distribution function models to the overall experimental curve. The initial fitting
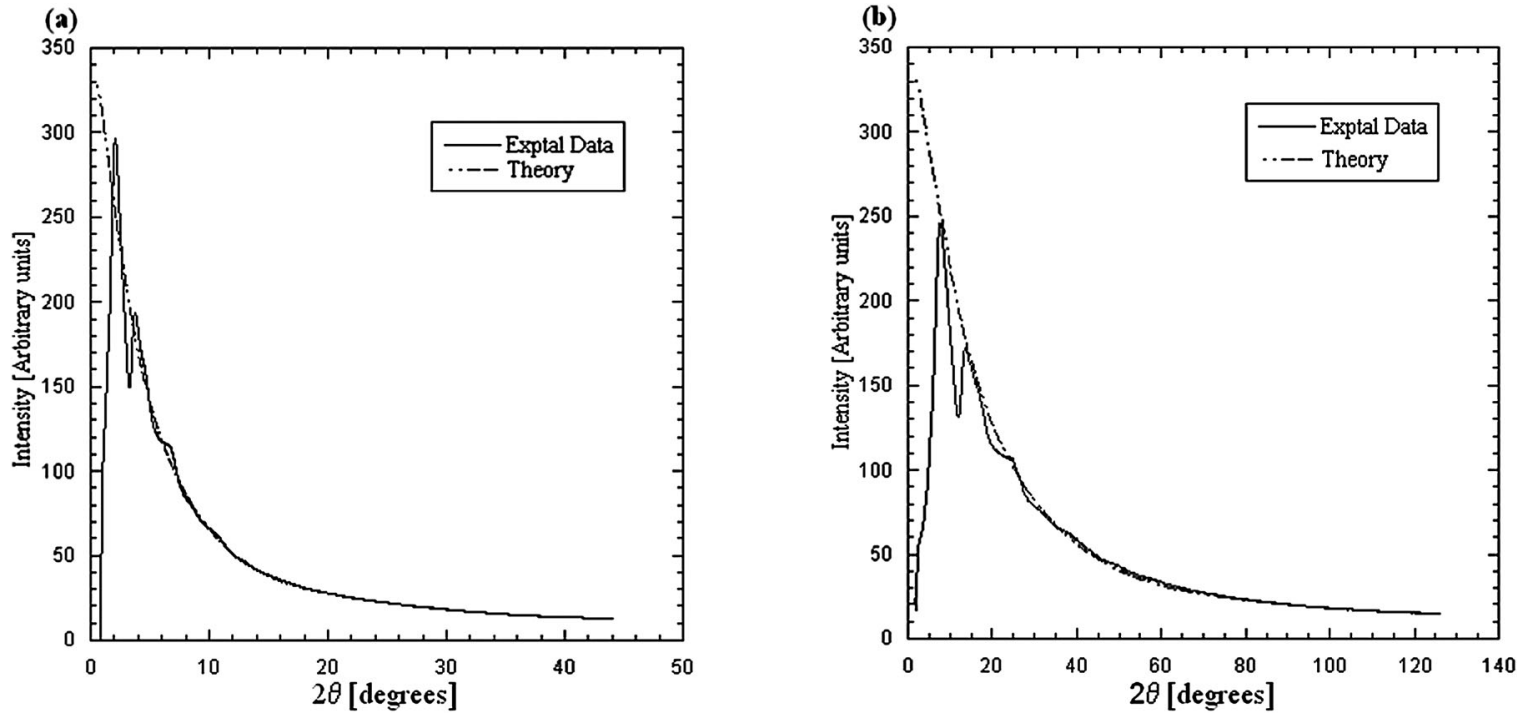

Fig. 1 Examples of the corrected experimental intensity profile (solid lines) fit to the theoretical sum of the self-scattering and Compton contributions (dashed lines) as a function of $2 \theta$ for the co-doped rare-earth sample, $\left(\mathrm{Ce}_{2} \mathrm{O}_{3}\right)_{0.178}\left(\mathrm{Er}_{2} \mathrm{O}_{3}\right)_{0.043}\left(\mathrm{P}_{2} \mathrm{O}_{5}\right)_{0.779}$, measured at the (a) ESRF; (b) SRS. 
values were also tested for robustness to possible false minima by performing additional test refinements which involved displacing these starting values by a tolerance level that maintains a parameter range which is closer to its parent correlation than its adjacent correlation in real-space; results were consistent with those from the original refinements.

Error estimation of the fitted values was conducted using an iterative visual inspection method in which the fitted values were displaced by successive amounts from the fitted correlation until a difference was observable. This method was employed since one assumes that statistical uncertainties, solely associated with the numerical fitting, will at least represent a lower bound of the true error which emanates from many factors that are difficult to quantify. Where there is substantial overlap of real-space Gaussian profiles, one must of course proceed with particular caution over and above these lower bounded errors, relying only on the $R_{i j}$ values since $N_{i j}$ and $\sigma_{i j}$, being correlated, are subject to inherent modeling limitations of this data analysis method. Moreover, while it is generally a good assumption to model atomic pair-wise correlations of an amorphous material according to a normal distribution, it is conceivable that slight deviations from a Gaussian profile could also occur. Despite such limitations, it is very encouraging that this method has afforded good consistency, especially in $R_{i j}$ values, in many other structural reports on this family of glasses, not only in diffraction measurements ${ }^{13,14}$ but in results that emanate from a range of materials characterization techniques. ${ }^{13-15,19}$ Accordingly, such limitations of the Gaskill approach are found to be acceptable for the analysis of this family of compounds, pending a realistic interpretation of these errors as discussed further herein.

\section{Results}

\section{Co-doped rare-earth phosphate glasses}

The X-ray interference function, $i(Q)$, for each co-doped rareearth phosphate sample is shown in Fig. 2. The ESRF $i(Q)$ profiles are of good quality with reliable data extending out to $Q_{\max }=28 \AA^{-1}$, yielding a real-space resolution $\Delta r=0.22 \AA$, cf. $r \approx 2 \pi / Q_{\max }$. Meanwhile, the SRS interference functions only extend to $Q_{\max }=22.5 \AA^{-1}$, yielding a lower atomic resolution, $\Delta r=0.28 \AA$. The SRS results are of lower statistical quality, making a good fit with the atomic self-scattering curve difficult (Fig. 1b). The corresponding $i(Q)$ profiles are shown in Fig. $2 \mathrm{~b}$. The modelled and experimental $t(r)$ determined for each sample are found in Fig. 3. Tables 2, 3, and 4 give the resulting correlation values for $N_{i j}, R_{i j}$ and $\sigma_{i j}^{2}$ for the ESRF (Ce, Er) co-doped glasses, the SRS (Ce, Er) co-doped samples, and the (La, Nd) co-doped glasses, respectively. A total of thirteen atomic pair-wise correlations were modelled for each ESRF sample, compared with the modelling of eleven such correlations for the SRS data. The lower number of such correlations is due to the exclusion, from the SRS data analysis, of the Al-O correlation that arises from $\mathrm{Al}_{2} \mathrm{O}_{3}$ contamination from the crucible owing to the more limited data quality. The lower atomic resolution of the SRS data also confined the modelling of the
$\mathrm{PO}$ correlation to an average of $\mathrm{P}-\mathrm{O}$ and $\mathrm{P}=\mathrm{O}$ bond types, rather than distinguishing them into the constituent bridging $\left(\mathrm{P}-\mathrm{O}_{\mathrm{B}}\right)$ and terminal $\left(\mathrm{P}-\mathrm{O}_{\mathrm{T}}\right)$ Gaussians, respectively, which is typically only achieved with higher resolution data (e.g. ref. 13). Examples of how the individual Gaussian peaks fit the data for the sample compositions mentioned above can be seen in Fig. 4a-c. All experimental data were modelled out to an atomic separation of $\sim 4 \AA$. Beyond this point, the atomic pair-wise correlations overlap so much that accurate determinations of individual Gaussians, both in size and position, become impossible. The level of modeling achievable here is consistent with all previous work on this family of glasses. ${ }^{13,14}$

The small Al contamination resulted in a correspondingly small additional feature in $t(r)$ being found at an atomic separation of 1.8-2.0 $\AA$ which cannot be accounted for by considering R, P, and $\mathrm{O}$ pairwise correlations alone. Therefore, an Al-O correlation was included in all of the ESRF models, except for the $\left(\mathrm{La}_{2} \mathrm{O}_{3}\right)_{0.260}\left(\mathrm{Nd}_{2} \mathrm{O}_{3}\right)_{0.010}\left(\mathrm{P}_{2} \mathrm{O}_{5}\right)_{0.730}$ sample for which the Al-O signal was far too small to reasonably include in the model. In general, the Al-O peak is overpowered by the $\mathrm{P}-\mathrm{O}$ and $\mathrm{R}-\mathrm{O}$ correlations in the SRS data and could not be resolved, although its presence is suggested by the artificially large Debye-Waller factors associated with the $\mathrm{P}-\mathrm{O}$ and $\mathrm{Er}-\mathrm{O}$ correlations. Exceptionally, it was possible to model the $\mathrm{Al}-\mathrm{O}$ correlation in one of the SRS $\left[\left(\mathrm{Ce}_{2} \mathrm{O}_{3}\right)_{0.111}\left(\mathrm{Er}_{2} \mathrm{O}_{3}\right)_{0.108}\left(\mathrm{P}_{2} \mathrm{O}_{5}\right)_{0.781}\right]$ samples. All modelled $\mathrm{Al}-\mathrm{O}$ peaks assumed a molar weight fraction of $2 \%$. The coordination numbers of this correlation varied considerably, which is likely to be due, in part, to the assumed weight fraction; this variation may also arise from the consideration that three distinct $\mathrm{Al}^{3+}$ structural configurations are possible which feature 4-, 5-, or 6-fold coordinations. ${ }^{13,36-40}$

\section{Single rare-earth phosphate glasses}

Fig. 5 shows the X-ray interference functions, $i(Q)$, for each of the single rare-earth phosphate glasses, which are of good quality out to $Q_{\max }=28 \AA^{-1}$, giving a real-space resolution, $\Delta r=0.22 \AA$. Fig. 6 affords the corresponding modelled and experimental $t(r)$ determined for each sample, and the resulting atomic pairwise correlations are quantified in Table 5 . These values are largely consistent with those found in literature, ${ }^{11-18}$ noting that some uncertainty arises in the estimation of the coordination numbers for all samples due to the effects of overlapping correlations. To minimize this particular problem, suitable values taken from literature were used as starting parameters, which were then adjusted as needed in order to obtain agreement with the experimental curve. A total of nine correlations were modelled; an example of how the individual Gaussian peaks fit the data is given for the $\left(\mathrm{Sm}_{2} \mathrm{O}_{3}\right)_{0.205}\left(\mathrm{P}_{2} \mathrm{O}_{5}\right)_{0.795}$ sample in Fig. $4 \mathrm{~d}$. The experimental data were fully modelled out to an atomic separation of $\sim 4 \AA$.

\section{Discussion}

\section{Influence of rare-earth co-doping on the local structure of rare-earth phosphate glasses}

In this section, the results for (Ce, Er) rare-earth co-doped glasses are considered first since those from the (La, Nd) 

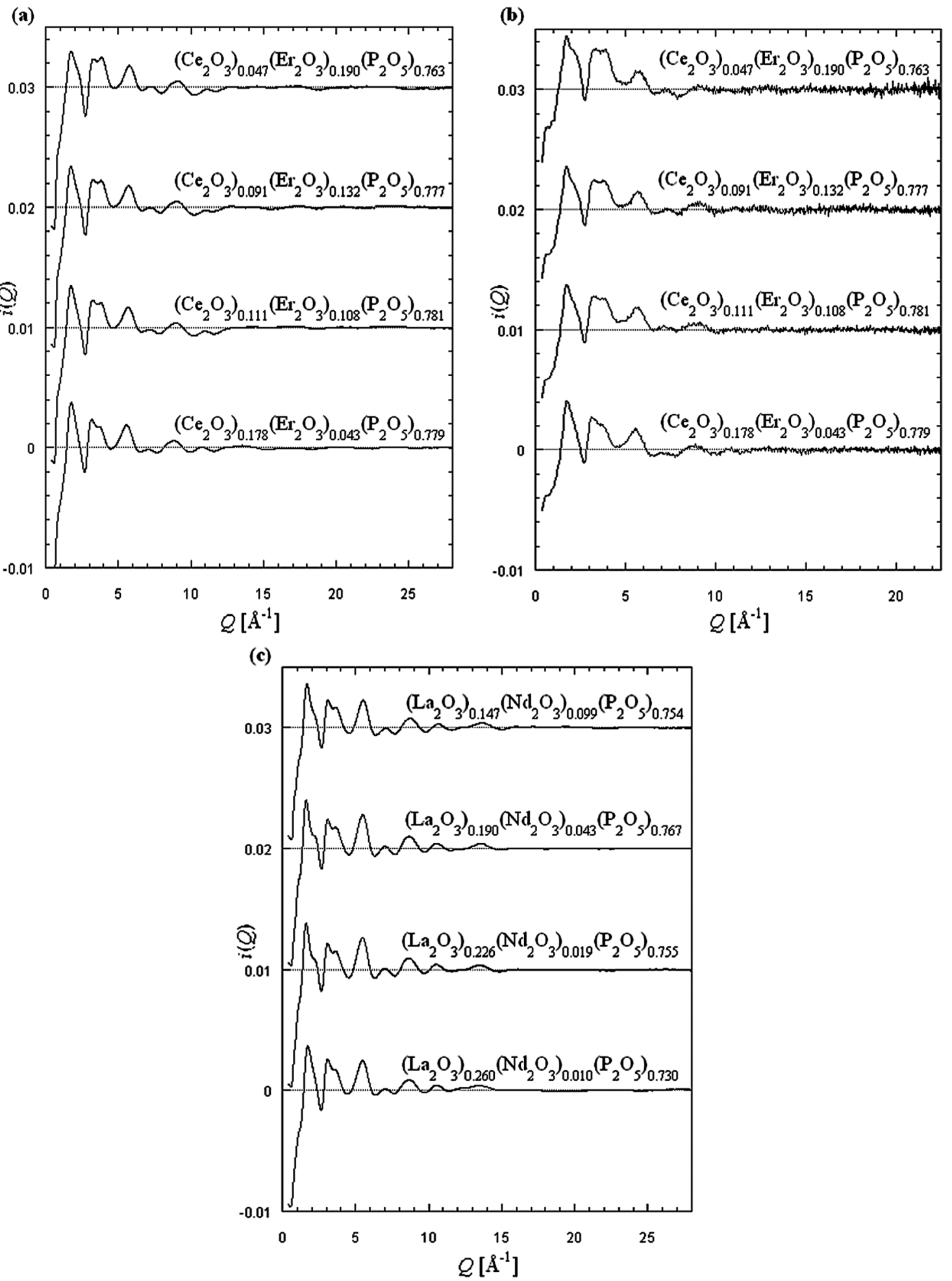

Fig. 2 Interference functions, $i(Q)$, for all co-doped rare-earth phosphate glasses of the (a) (Ce, Er) mix (ESRF), (b) (Ce, Er) mix (SRS), and (c) (La, Nd) mix (ESRF). Interference function curves have been offset from zero to avoid stacking.

phosphate glasses possess a much lower level of heavier rare-earth doping. Therefore, any structural perturbations should be easier to distinguish in the (Ce, Er) samples. While there are two (Ce, Er) datasets available, this section focuses exclusively on the ESRF data since this is deemed to be of higher quality than the SRS data. A dedicated, technicallyminded, comparison between the ESRF and SRS data is reserved for Section 4.2. 
(a)

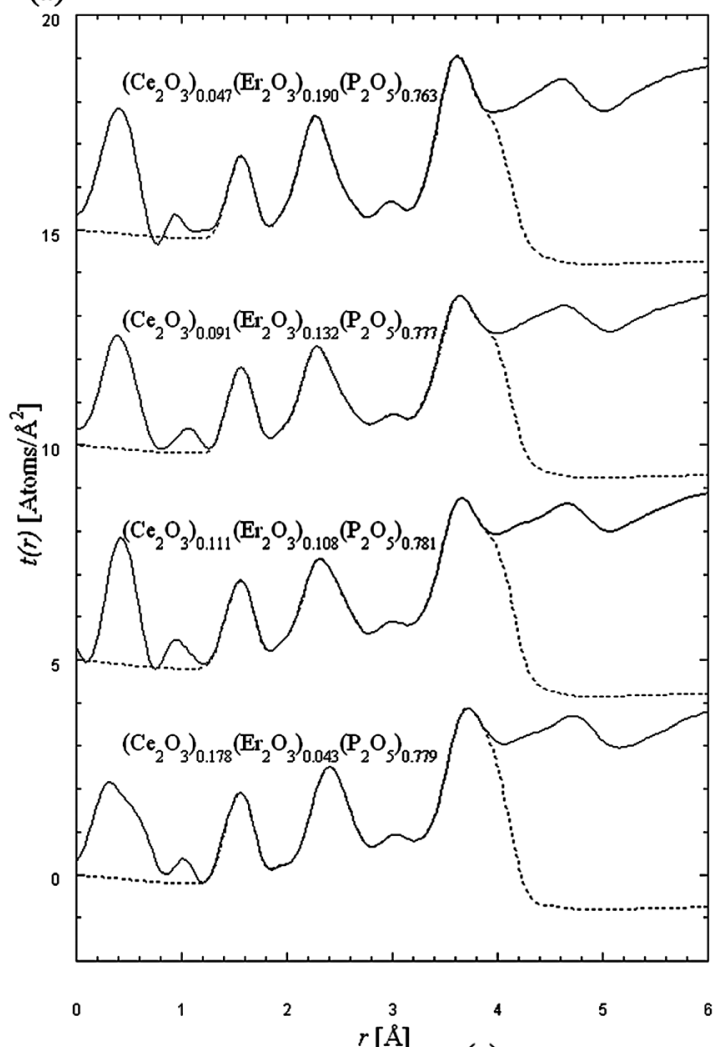

(b)

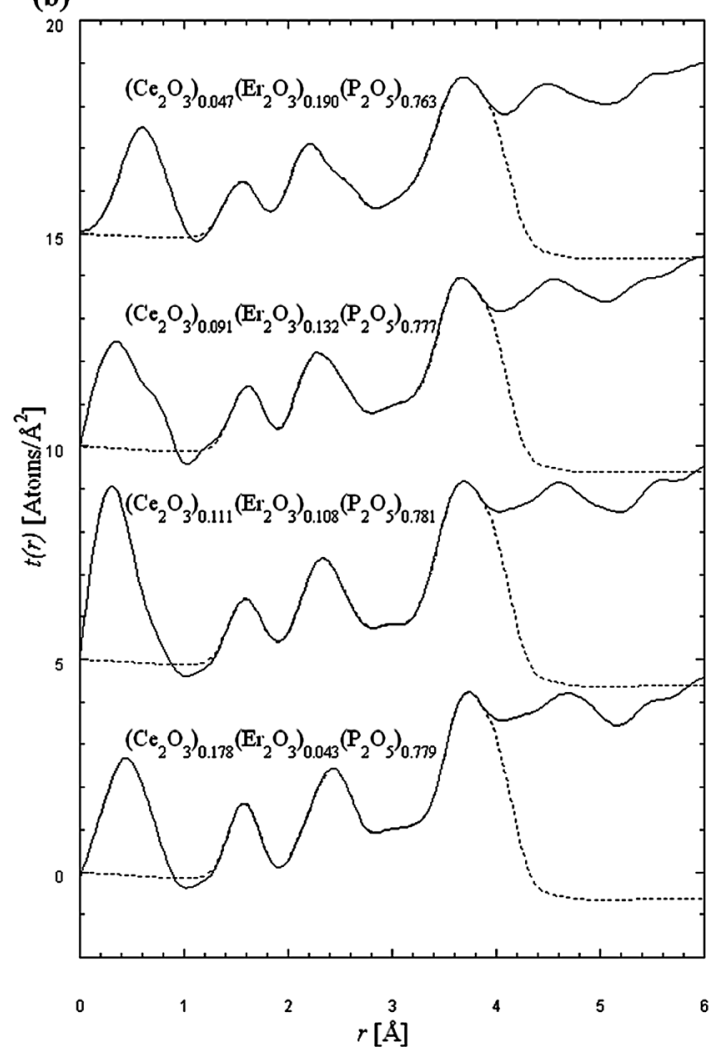

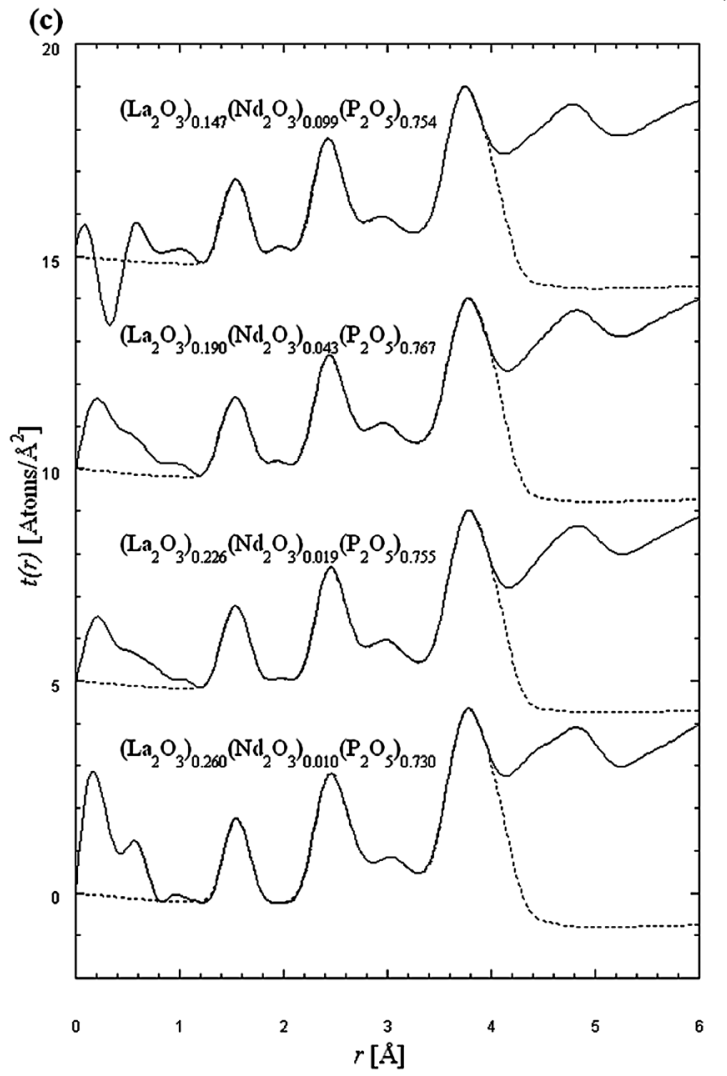

Fig. $3 t(r)$ profiles for each of the co-doped rare-earth phosphate glasses (a) (Ce, Er) mix (ESRF), (b) (Ce, Er) mix (SRS), and (c) (La, Nd) mix (ESRF). Solid lines represent the experimental data, dotted lines are the corresponding models. $t(r)$ curves have been offset from zero to avoid stacking. 
Table 2 Coordination numbers, $N$, atomic separations, $R(\AA)$, and Debye-Waller factors, $\sigma^{2}\left(\AA^{2}\right)$, for each of the modelled pairwise correlation functions for the (Ce, Er) co-doped rare-earth phosphate glasses, based on the X-ray diffraction data from ESRF. Where pairwise correlations present a small contribution relative to the overall pair distribution function, only the $R$ parameters give realistic values, although all modelled parameters are presented for completeness. Error analysis for these parameters is discussed in Section 2.3

\begin{tabular}{|c|c|c|c|c|c|c|c|c|c|c|c|c|c|}
\hline \multirow[b]{2}{*}{ Ce composition } & \multirow[b]{2}{*}{ Er composition } & \multicolumn{3}{|l|}{$\mathrm{P}=\mathrm{O}_{\mathrm{T}}$} & \multicolumn{3}{|l|}{$\mathrm{P}-\mathrm{O}_{\mathrm{B}}$} & \multicolumn{3}{|l|}{ Er-O } & \multicolumn{3}{|l|}{$\mathrm{Ce}-\mathrm{O}$} \\
\hline & & $N$ & $R$ & $\sigma^{2}$ & $N$ & $R$ & $\sigma^{2}$ & $N$ & $R$ & $\sigma^{2}$ & $N$ & $R$ & $\sigma^{2}$ \\
\hline - & 0.239 & $2.11(8)$ & $1.50(1)$ & $0.001(1)$ & $1.83(8)$ & $1.61(1)$ & $0.003(2)$ & $5.9(1)$ & $2.25(1)$ & $0.010(1)$ & - & - & - \\
\hline 0.091 & 0.132 & $1.85(6)$ & $1.49(1)$ & $0.001(1)$ & $2.15(8)$ & $1.63(1)$ & $0.001(1)$ & $5.9(2)$ & $2.24(1)$ & $0.008(1)$ & $5.8(5)$ & $2.43(2)$ & $0.006(2)$ \\
\hline 0.111 & 0.108 & $2.00(4)$ & 1.48(1) & $0.004(2)$ & $2.04(7)$ & $1.62(1)$ & $0.002(1)$ & $5.2(2)$ & $2.23(1)$ & $0.012(3)$ & $6.7(3)$ & $2.39(1)$ & $0.013(2)$ \\
\hline 0.178 & 0.043 & $1.90(4)$ & $1.47(1)$ & $0.002(1)$ & $2.15(4)$ & $1.62(1)$ & $0.001(1)$ & $6.7(8)$ & $2.23(2)$ & $0.006(3)$ & $6.4(2)$ & $2.42(1)$ & $0.011(1)$ \\
\hline 0.197 & - & $1.98(7)$ & $1.50(1)$ & $0.002(1)$ & $1.97(9)$ & $1.61(1)$ & $0.006(1)$ & - & - & - & $6.3(1)$ & $2.42(1)$ & $0.011(1)$ \\
\hline Ce composition & Er composition & $N$ & $R$ & $\sigma^{2}$ & $N$ & $R$ & $\sigma^{2}$ & $N$ & $R$ & $\sigma^{2}$ & $N$ & $R$ & $\sigma^{2}$ \\
\hline- & 0.239 & $4.4(4)$ & $2.55(2)$ & $0.014(6)$ & $3.7(2)$ & $2.97(1)$ & $0.006(2)$ & $6.6(5)$ & $3.26(1)$ & $0.012(3)$ & - & - & - \\
\hline 0.047 & 0.190 & $3.9(2)$ & $2.60(1)$ & $0.005(3)$ & $3.1(2)$ & 2.98(1) & $0.011(2)$ & $5.2(2)$ & $3.21(2)$ & $0.018(3)$ & $5.3(3)$ & $3.34(1)$ & $0.010(4)$ \\
\hline 0.091 & 0.132 & $4.5(2)$ & $2.63(1)$ & $0.008(2)$ & $2.9(1)$ & 2.99(1) & $0.011(2)$ & $5.1(2)$ & $3.27(1)$ & $0.017(3)$ & $5.1(2)$ & $3.32(1)$ & $0.015(3)$ \\
\hline 0.111 & 0.108 & $5.6(2)$ & $2.60(1)$ & $0.011(3)$ & $3.2(1)$ & $2.98(1)$ & $0.011(1)$ & $4.8(2)$ & $3.19(1)$ & $0.010(1)$ & $5.2(2)$ & $3.32(1)$ & $0.012(2)$ \\
\hline Ce composition & Er composition & $N$ & $R$ & $\sigma^{2}$ & $N$ & $R$ & $\sigma^{2}$ & $N$ & $R$ & $\sigma^{2}$ & $N$ & $R$ & $\sigma^{2}$ \\
\hline - & 0.239 & $8.3(2)$ & $3.57(1)$ & $0.025(1)$ & - & - & - & $11(1)$ & $3.95(2)$ & $0.025(5)$ & - & - & - \\
\hline 0.047 & 0.190 & $7.0(2)$ & $3.59(1)$ & $0.021(1)$ & $6.6(8)$ & $3.70(4)$ & $0.020(5)$ & $12(1)$ & $3.97(1)$ & $0.020(4)$ & $16(3)$ & $4.00(4)$ & $0.020(12)$ \\
\hline 0.091 & 0.132 & $6.4(1)$ & $3.59(1)$ & $0.021(1)$ & $6.5(1)$ & $3.71(1)$ & $0.022(1)$ & $11(1)$ & $3.98(1)$ & $0.017(2)$ & $12(2)$ & 4.01(1) & $0.020(4)$ \\
\hline 0.111 & 0.108 & $6.7(2)$ & 3.53(1) & $0.017(1)$ & $8.0(2)$ & 3.73(1) & $0.015(1)$ & $12(2)$ & $3.98(1)$ & $0.020(2)$ & $13(2)$ & $4.03(2)$ & $0.018(3)$ \\
\hline 0.178 & 0.043 & $8.2(6)$ & $3.54(1)$ & $0.020(2)$ & $7.8(1)$ & 3.71(1) & $0.023(1)$ & $12(2)$ & $3.98(2)$ & $0.016(9)$ & $12(1)$ & $4.00(1)$ & $0.018(3)$ \\
\hline 0.197 & - & - & - & - & $7.7(1)$ & $3.71(1)$ & $0.025(1)$ & - & - & - & $12(1)$ & $4.00(1)$ & $0.021(3)$ \\
\hline
\end{tabular}

\begin{tabular}{|c|c|c|c|c|c|}
\hline \multirow[b]{2}{*}{ Ce composition } & \multirow[b]{2}{*}{ Er composition } & \multicolumn{3}{|l|}{$\mathrm{Al}-\mathrm{O}$} & \multirow[b]{2}{*}{$\mathrm{Al}_{2} \mathrm{O}_{3}$ fraction wt $\%$} \\
\hline & & $N$ & $R$ & $\sigma^{2}$ & \\
\hline- & 0.239 & $5.5(9)$ & $1.96(4)$ & $0.001(2)$ & 2 \\
\hline 0.111 & 0.108 & $12.0(6)$ & $1.94(2)$ & $0.002(2)$ & 2 \\
\hline 0.178 & 0.043 & $11.4(5)$ & $1.94(2)$ & $0.004(2)$ & 2 \\
\hline 0.197 & - & $6.6(4)$ & $1.92(1)$ & $0.001(1)$ & 2 \\
\hline
\end{tabular}

\section{Effects of erbium-doping on the local structure of cerium phosphate glasses}

The immediate rare-earth environment. Given that the rareearth co-doping of these phosphate glasses is specific to the $\mathrm{R}^{3+}$ ion, one would expect that the primary structural perturbations caused by this co-doping, relative to the single rare-earth parent structure, will lie in the immediate vicinity of the $\mathrm{R}^{3+}$ ion. Accordingly, the largest structural perturbations are most likely to be associated with the $\mathrm{R}-\mathrm{O}$ atomic pairwise correlation. This anticipation is heightened by the fact that the compositionweighted scattering factors for the $\mathrm{R}-\mathrm{O}$ pairwise correlation are such that the $\mathrm{R}-\mathrm{O}$ peak is one of the strongest in the $t(r)$ profile; consequently, it has the greatest capacity to distinguish structural perturbations due to rare-earth co-doping. It is also worth noting that the R-O contribution to the $t(r)$ profile only contains significant overlap with contributions from one other correlation: $\mathrm{O}(\mathrm{P}) \mathrm{O}$, which has a much lower intensity so that $\mathrm{R}-\mathrm{O}$ features predominate (see Fig. 4).
Table 2 features details of the modelled $\mathrm{R}-\mathrm{O}$ parameters as a function of varying (Ce, Er) composition. The $R_{\mathrm{RO}}$ values are considered first since this is the most accurate of the three parameters. Analysis of $R_{\mathrm{RO}}$ in the context of the progressive increase in Ce composition, relative to the concurrent decrease in Er composition, evidences an invariance of $\mathrm{R}-\mathrm{O}$ separation over this range of compositions studied. Indeed, these observed $R_{\mathrm{RO}}$ values are also identical to those of the single-rare-earth phosphate glasses within experimental error, $c f$. $R_{\mathrm{RO}}$ for Ce, $x=0.197$, Er, $x=0.239$, in Table 5 and previous $R_{\mathrm{RO}}$ results. ${ }^{13,14}$ The associated coordination numbers, $N_{\text {RO }}$, also show no change, although any observed changes to $N_{\mathrm{RO}}$ alone would be inconclusive since the experimental uncertainties are too large to distinguish possible structural changes, owing to the effect on the peak area of significant overlap with peaks from other pairwise correlations.

The $\mathrm{O}(\mathrm{R}) \mathrm{O}$ correlation can sometimes act as a corroborative parameter for possible $N_{\mathrm{RO}}$ coordination number changes since a direct corollary to an increase in oxygen coordination about 


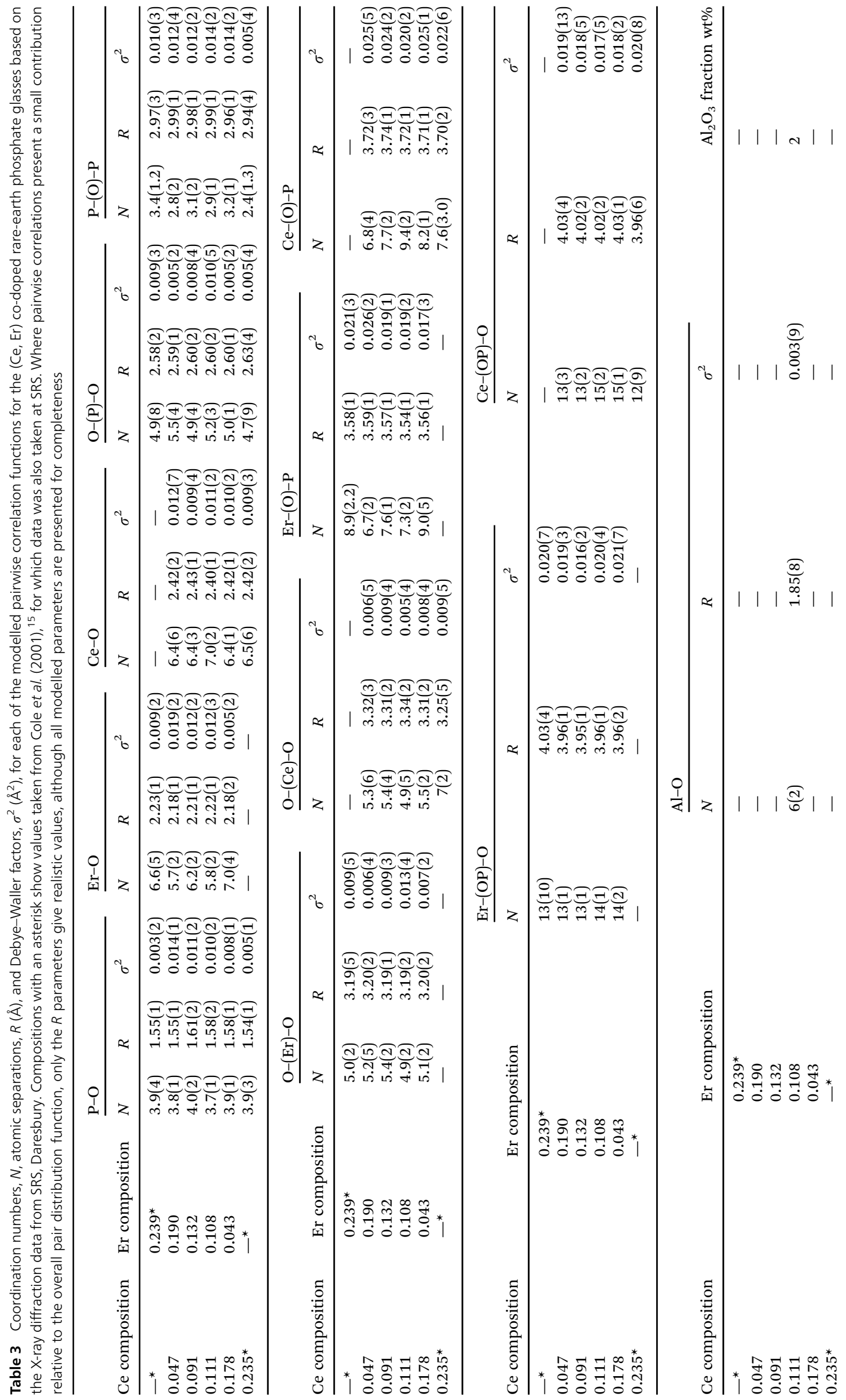


Table 4 Coordination numbers, $N$, atomic separations, $R(\AA)$, and Debye-Waller factors, $\sigma^{2}\left(\AA^{2}\right)$, for each of the (La, Nd) modelled pairwise correlation functions for co-doped rare-earth phosphate glasses, based on the X-ray diffraction data from ESRF, Grenoble. The singly-doped Nd sample, denoted by an asterisk, shows values taken from Cole et al. (2001) $)^{15}$ - note these values were derived from data taken at the lower-energy SRS, Daresbury facility, and do not distinguish between the PO and $\mathrm{PO}_{\mathrm{B}}$ peaks, giving the average instead. Errors for the two lowest $\mathrm{Nd}$ concentration samples for the $\mathrm{Nd}(\mathrm{OP}) \mathrm{O}$ pair (denoted by a double asterisk) were unable to be determined, owing to the overpowering $\mathrm{La}(\mathrm{O}) \mathrm{P}$, and $\mathrm{La}(\mathrm{OP}) \mathrm{O}$ correlations. These two peaks were given reasonable values with respect to literature to assist in the modelling of the surrounding dominant peaks. Where pairwise correlations present a small contribution relative to the overall pair distribution function, only the $R$ parameters give realistic values, although all modelled parameters are presented for completeness. Error analysis for these parameters is discussed in Section 2.3

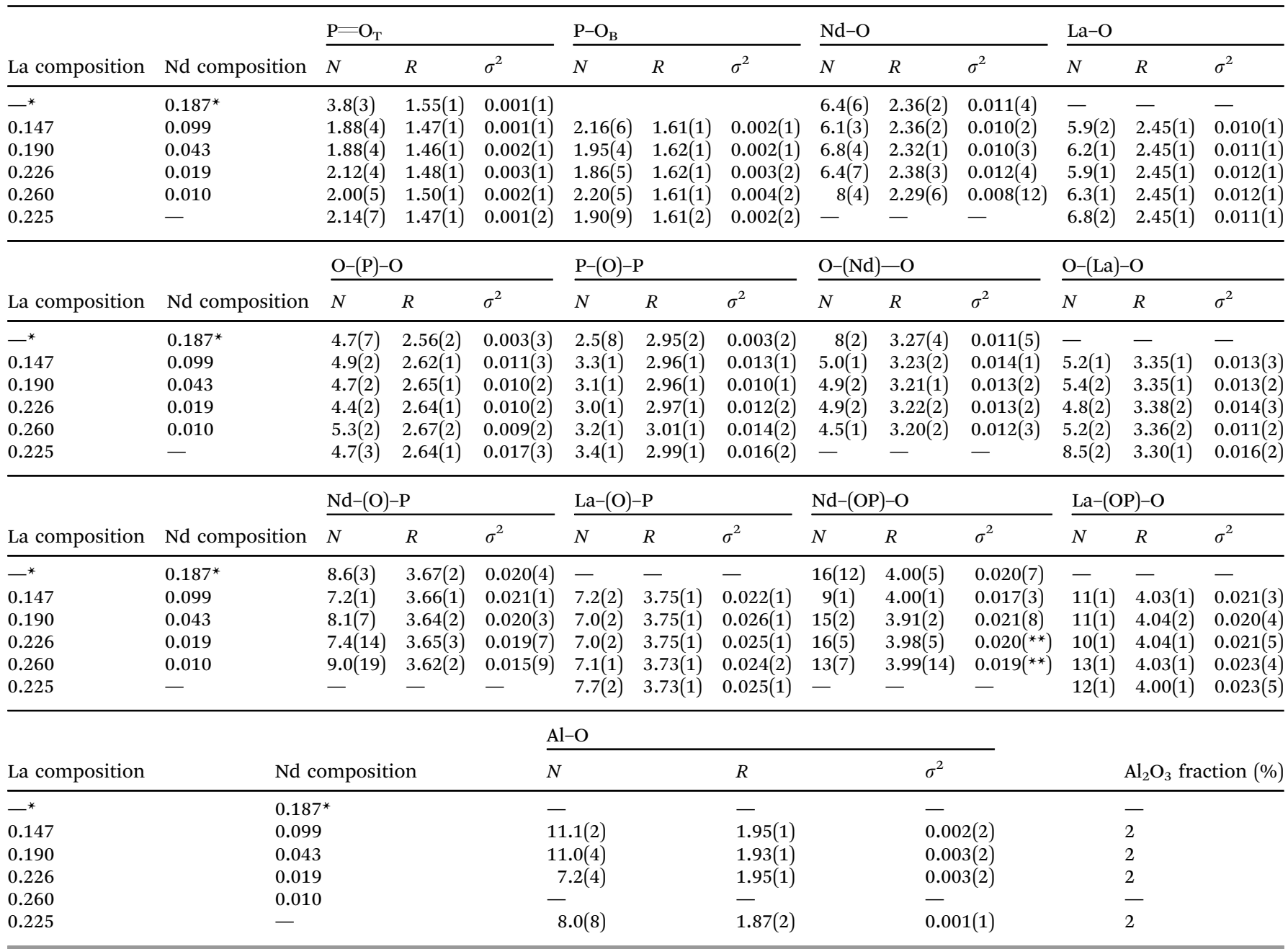

the rare-earth ion is a contraction of the average $\mathrm{O} \hat{R} \mathrm{O}$ angle; consequently, the $\mathrm{O}(\mathrm{R}) \mathrm{O}$ separation would decrease according to simple trigonometric outcomes. It is clear from Table 2 that there is no significant change in the observed $R_{\mathrm{ORO}}$ separation.

If the co-doping were to disrupt the immediate rare-earth environment, one would also expect a corresponding increase in the static-disorder contribution to the Debye-Waller factor. However, one does not observe this; rather, $\sigma_{\mathrm{RO}}{ }^{2}$ and $\sigma_{\mathrm{ORO}}{ }^{2}$ for all co-doped samples are not only all the same within experimental error, they also do not differ from the analogous $\sigma^{2}$ values for the singular rare-earth phosphate glasses.

The only other atomic pairwise correlation that may help us in this enquiry is the $\mathrm{R}(\mathrm{OP}) \mathrm{O}$ correlation. However, the accuracy of any of the associated parameters is too poor to apply any structural distinction of the level sought here since its peak lies centred at about $4 \AA$; this is on the boundary of modelling capabilities with this series of glasses, owing to the numerous overlapping pairwise correlations in the region of this separation.

In summary, from all relevant evidence in this data, one can infer that the co-doping of Er into a Ce phosphate glass matrix does not significantly disrupt the local structure of the glass: the Er dopant simply appears as an additional, compositionweighted, characteristic Er-X pairwise correlation which co-exists with the otherwise unaffected $\mathrm{Ce}-\mathrm{X}$ correlations. Such structural invariance in the immediate rare-earth environment implies that the well-known large open-framework and rigid nature of these glasses is able to accommodate rare-earth dopants without any disruption to their fundamental local structure, even up to a point where the dopant starts to dominate the rare-earth component of the glass composition.

This study represents the first structural evidence of rareearth doping effects in these glasses. It is worth noting, however, that the incorporation of a main-group metal oxide, 

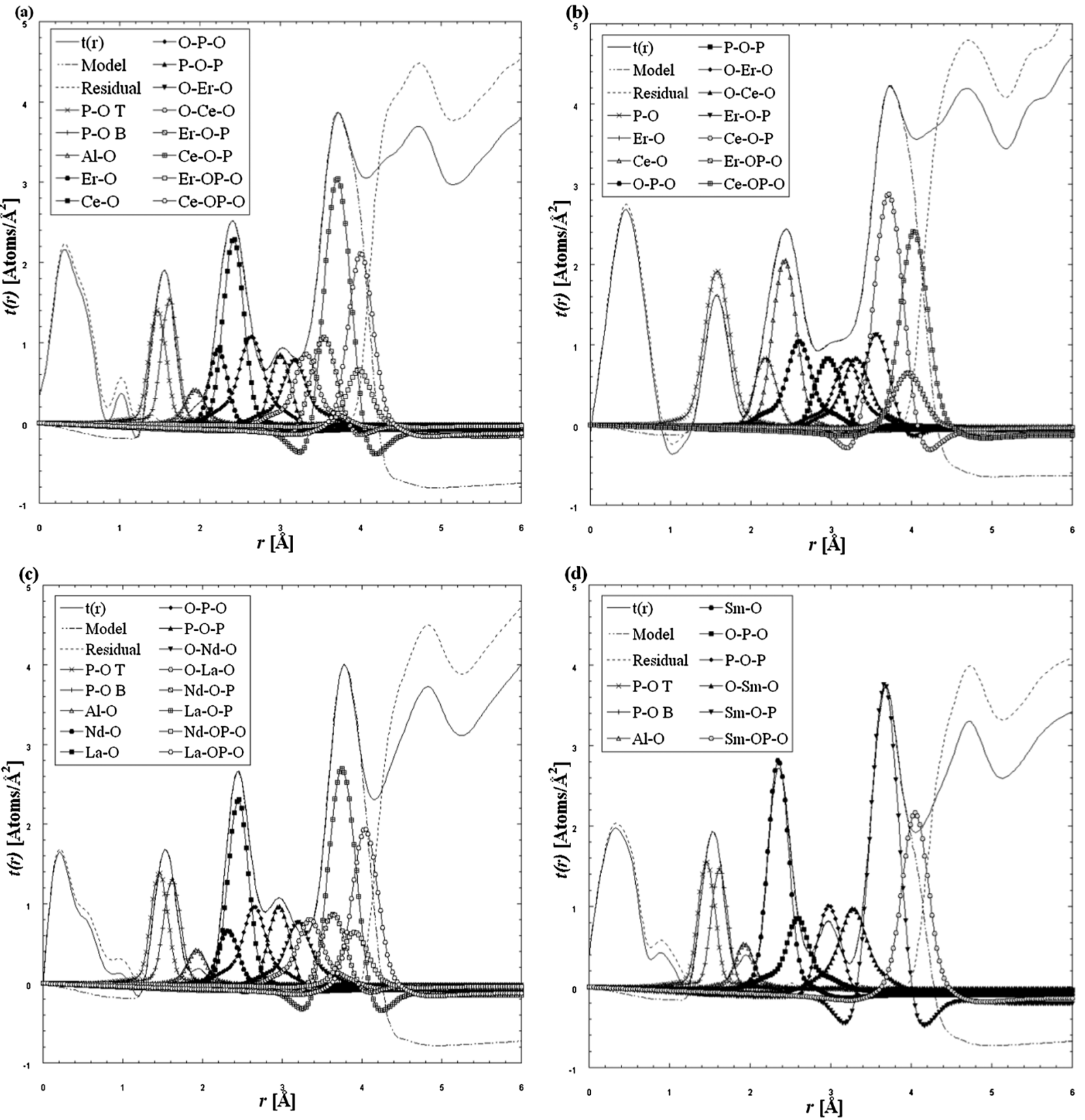

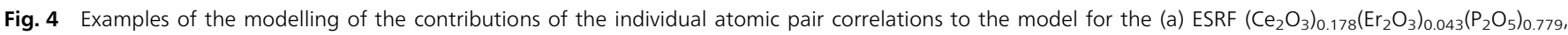
(b) SRS $\left(\mathrm{Ce}_{2} \mathrm{O}_{3}\right)_{0.178}\left(\mathrm{Er}_{2} \mathrm{O}_{3}\right)_{0.043}\left(\mathrm{P}_{2} \mathrm{O}_{5}\right)_{0.779}$, (c) $\left(\mathrm{La}_{2} \mathrm{O}_{3}\right)_{0.190}\left(\mathrm{Nd}_{2} \mathrm{O}_{3}\right)_{0.043}\left(\mathrm{P}_{2} \mathrm{O}_{5}\right)_{0.767}$, and (d) $\left(\mathrm{Sm}_{2} \mathrm{O}_{3}\right)_{0.205}\left(\mathrm{P}_{2} \mathrm{O}_{5}\right)_{0.795}$ samples.

$\mathrm{Al}_{2} \mathrm{O}_{3}$, into a rare-earth phosphate network has been achieved previously, also without structural compromise to the immediate rare-earth environment; this is irrespective of whether $\mathrm{Al}$ is present in small $\left(1-2 \mathrm{wt} \% \mathrm{Al}_{2} \mathrm{O}_{3} ;{ }^{13}\right)$ or large $\left(17 \mathrm{wt} \% \mathrm{Al}_{2} \mathrm{O}_{3} ;{ }^{40}\right)$ quantities. However, the specific reference to rare-earth doping is important on account of its different ionic size, ion substitution site and electronic factors on the one hand, and its aforementioned key influence on the lasing properties on the other hand.

The phosphate network. Having established the effects of rare-earth doping on the immediate rare-earth environment, it needed to be assessed if this structural invariance with rare-earth doping extended to the overall phosphate network. This hypothesis could be tested by analysing the respective $\mathrm{R}(\mathrm{O}) \mathrm{P}$ and $\mathrm{P}-\mathrm{O}$ pairwise correlation parameters.

Table 2 readily demonstrates that all bridging or terminal phosphate bond parameters are invariant with changing co-dopant concentration, and indeed with those of singular rare-earth phosphate glasses (Table 5). These findings alone strongly suggest that the phosphate network is unperturbed by the effect of co-doping, at least up to the level of doping presented here, since the $\mathrm{P}-\mathrm{O}$ atomic pairwise correlation is typically the most reliable of all correlations in these rare-earth phosphate glasses; this is because this correlation is not 


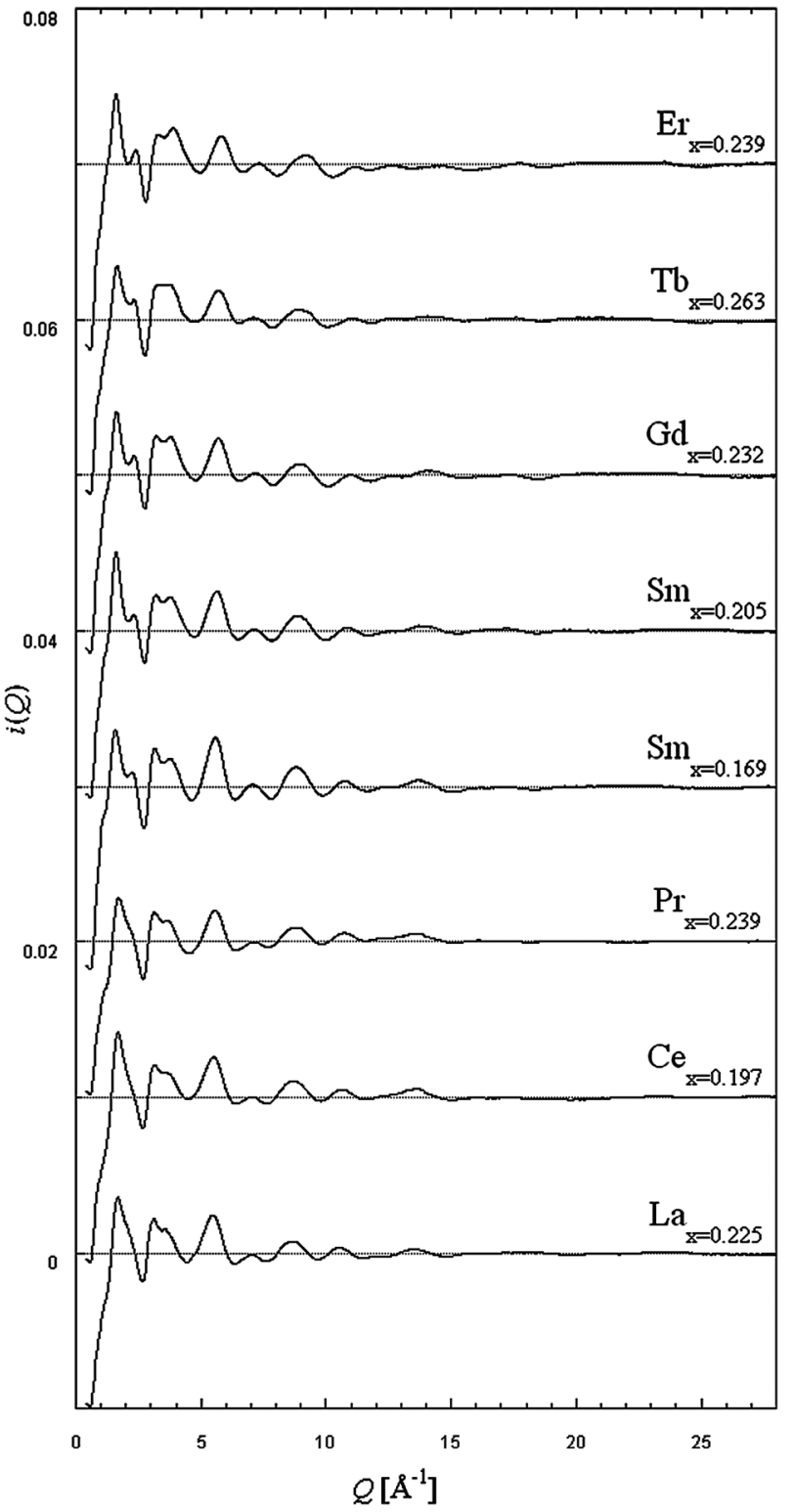

Fig. 5 The interference functions, $i(Q)$, for all of the single rare-earth phosphate glasses, $\left(\mathrm{R}_{2} \mathrm{O}_{3}\right)_{x}\left(\mathrm{P}_{2} \mathrm{O}_{5}\right)_{1-x}, \mathrm{R}=\mathrm{La}, \mathrm{Ce}, \mathrm{Pr}, \mathrm{Sm}, \mathrm{Gd}, \mathrm{Tb}, \mathrm{Er}$. Interference function curves have been offset from zero to avoid stacking.

contaminated by any overlapping pairwise correlations owing to the fact that $\mathrm{P}-\mathrm{O}$ is the shortest separation amongst all possible correlations.

Nonetheless, it is always prudent to corroborate findings from one correlation by checking for consistent effects in related correlations. In this regard, the R $\cdots \mathrm{P}$ correlation can afford such verification since, while its pairwise separation is close to the upper boundary of modelling feasibility owing to the increasing number of overlapping correlations at this separation, the $\mathrm{R} \cdots \mathrm{P}$ peak is very intense relative to most other peaks in the $t(r)$ profile (see Fig. 4 ). This intensity owes itself to the very favourable combination of scattering factors and stoichiometric weighting associated with $\mathrm{R}$ and $\mathrm{P}$ in these glasses. Accordingly, analysis of the R..P pairwise

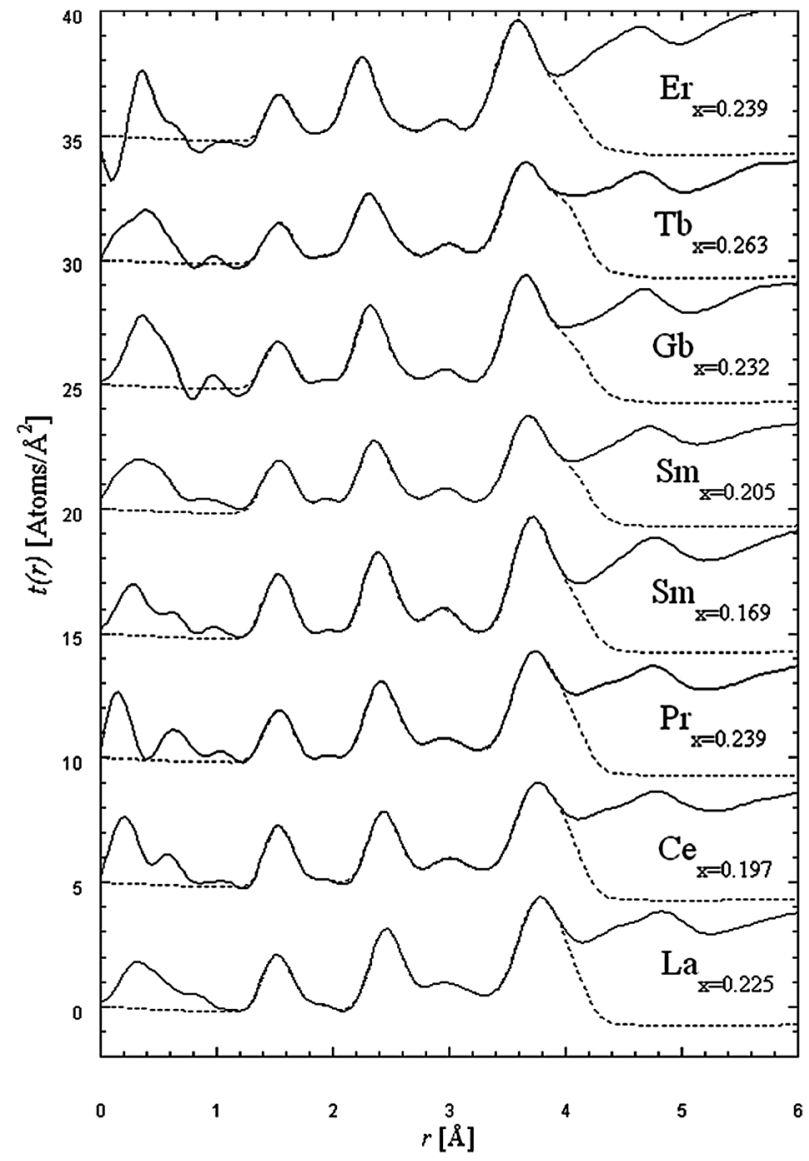

Fig. $6 t(r)$ profiles for each of the single rare-earth phosphate glasses. Solid lines represent the experimental data, dotted lines are the corresponding models. $t(r)$ curves have been offset from zero to avoid stacking.

correlation parameters revealed no significant change as a function of varying co-dopant concentration. For completeness, the other pairwise correlations that have an association with the phosphate network and have not been considered yet, i.e. $\mathrm{O}-(\mathrm{P})-\mathrm{O}, \mathrm{P}-(\mathrm{O})-\mathrm{P}$, and $\mathrm{R}-(\mathrm{OP})-\mathrm{O}$, were permitted a cursory investigation - cursory, because the interpretation of the parameters from correlations of such low intensity or high correlation overlap is somewhat suspect when considered in isolation; nonetheless, the results were consistent with others: all of their parameters in Table 2 also showed invariance to co-doping effects.

\section{Effects of neodymium-doping on the local structure of lanthanum phosphate glasses}

Before formulating an overall general conclusion about rareearth co-doping effects in rare-earth phosphate glasses, corresponding comparisons were made on the (La, $\mathrm{Nd}$ ) co-doped phosphate glasses. Their parameters, listed in Table 4, were compared with those from the (Ce, Er) results (Table 2) and single rare-earth phosphate glass data (Table 5). No discernible changes with varying co-dopant concentration were identified within experimental uncertainty. Given the results from the (Ce, Er) data analysis, this analogous result on the (La, Nd) 


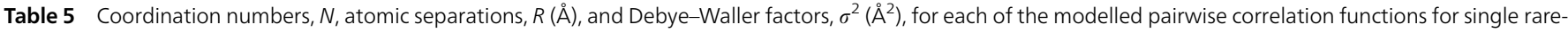

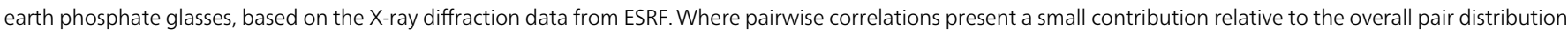

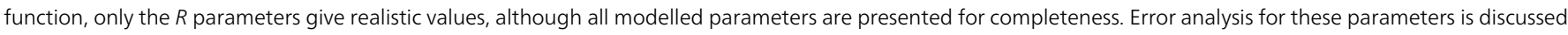
in Section 2.3

\begin{tabular}{|c|c|c|c|c|c|c|c|c|c|c|c|c|c|}
\hline \multirow[b]{2}{*}{$\mathrm{RE}$} & \multirow[b]{2}{*}{ Composition } & \multicolumn{3}{|l|}{$\mathrm{P}=\mathrm{O}_{\mathrm{T}}$} & \multicolumn{3}{|l|}{$\mathrm{P}-\mathrm{O}_{\mathrm{B}}$} & \multicolumn{3}{|l|}{$\underline{\mathrm{R}-\mathrm{O}}$} & \multicolumn{3}{|c|}{$\mathrm{O}-(\mathrm{P})-\mathrm{O}$} \\
\hline & & $N$ & $R$ & $\sigma^{2}$ & $N$ & $R$ & $\sigma^{2}$ & $N$ & $R$ & $\sigma^{2}$ & $N$ & $R$ & $\sigma^{2}$ \\
\hline $\mathrm{La}$ & 0.225 & $2.14(7)$ & $1.47(1)$ & $0.001(2)$ & $1.90(9)$ & $1.61(2)$ & $0.002(2)$ & $6.8(2)$ & $2.45(1)$ & $0.011(1)$ & $4.7(3)$ & $2.64(1)$ & $0.017(3)$ \\
\hline $\mathrm{Ce}$ & 0.197 & $1.98(7)$ & $1.50(1)$ & $0.002(1)$ & $1.97(9)$ & $1.61(1)$ & $0.006(1)$ & $6.3(1)$ & $2.42(1)$ & $0.011(1)$ & $4.2(2)$ & 2.61(1) & $0.013(3)$ \\
\hline $\operatorname{Pr}$ & 0.239 & $1.84(6)$ & $1.47(1)$ & $0.002(2)$ & $2.14(7)$ & $1.60(1)$ & $0.001(1)$ & $6.2(2)$ & $2.40(1)$ & $0.010(1)$ & $4.8(3)$ & $2.60(1)$ & $0.008(3)$ \\
\hline $\mathrm{Sm}$ & 0.169 & $2.00(5)$ & $1.47(1)$ & $0.002(1)$ & $2.00(6)$ & $1.61(1)$ & $0.002(1)$ & $6.5(4)$ & $2.37(1)$ & $0.008(2)$ & $5.4(2)$ & $2.56(1)$ & $0.009(3)$ \\
\hline $\mathrm{Sm}$ & 0.205 & $2.02(4)$ & $1.46(1)$ & $0.002(1)$ & $2.02(5)$ & $1.62(1)$ & $0.001(1)$ & $6.0(1)$ & $2.35(1)$ & $0.011(1)$ & $3.9(2)$ & $2.59(1)$ & $0.009(3)$ \\
\hline Gd & 0.232 & $1.90(7)$ & $1.47(1)$ & $0.002(2)$ & $2.00(6)$ & $1.60(1)$ & $0.002(1)$ & $5.9(2)$ & $2.32(1)$ & $0.008(1)$ & $4.4(4)$ & $2.56(1)$ & $0.007(2)$ \\
\hline $\mathrm{Tb}$ & 0.263 & $1.88(6)$ & $1.48(1)$ & $0.002(2)$ & $2.00(7)$ & $1.60(1)$ & $0.002(1)$ & $5.4(1)$ & $2.31(2)$ & $0.012(1)$ & $4.3(3)$ & $2.57(1)$ & $0.009(3)$ \\
\hline \multirow[t]{2}{*}{$\mathrm{Er}$} & 0.239 & $2.11(8)$ & $1.50(1)$ & $0.001(1)$ & $1.83(8)$ & $1.61(1)$ & $0.003(2)$ & $5.9(1)$ & $2.25(1)$ & $0.010(1)$ & $4.4(4)$ & $2.55(2)$ & $0.014(6)$ \\
\hline & & \multicolumn{3}{|c|}{$\underline{\mathrm{P}-(\mathrm{O})-\mathrm{P}}$} & \multicolumn{3}{|c|}{$\mathrm{O}-(\mathrm{R})-\mathrm{O}$} & \multicolumn{3}{|c|}{$\underline{\mathrm{R}-(\mathrm{O})-\mathrm{P}}$} & \multicolumn{3}{|c|}{$\underline{\mathrm{R}-(\mathrm{OP})-\mathrm{O}}$} \\
\hline $\mathrm{RE}$ & Composition & $N$ & $R$ & $\sigma^{2}$ & $N$ & $R$ & $\sigma^{2}$ & $N$ & $R$ & $\sigma^{2}$ & $N$ & $R$ & $\sigma^{2}$ \\
\hline $\mathrm{La}$ & 0.225 & $3.4(1)$ & $2.99(1)$ & $0.016(2)$ & $8.5(2)$ & $3.30(1)$ & $0.016(2)$ & $7.7(2)$ & $3.73(1)$ & $0.025(1)$ & $12(1)$ & $4.00(1)$ & $0.023(5)$ \\
\hline $\mathrm{Ce}$ & 0.197 & $3.3(1)$ & $3.01(1)$ & $0.013(2)$ & $7.5(2)$ & $3.30(1)$ & $0.014(2)$ & $7.7(1)$ & $3.71(1)$ & $0.025(1)$ & $12(1)$ & $4.00(1)$ & $0.021(3)$ \\
\hline $\operatorname{Pr}$ & 0.239 & $3.3(1)$ & $2.98(1)$ & $0.013(2)$ & $7.6(2)$ & $3.28(1)$ & $0.015(2)$ & $7.9(1)$ & $3.70(1)$ & $0.025(1)$ & $11(1)$ & $4.01(1)$ & $0.021(2)$ \\
\hline $\mathrm{Sm}$ & 0.169 & $3.1(1)$ & $2.96(1)$ & $0.010(1)$ & $6.6(3)$ & $3.29(1)$ & $0.014(2)$ & $9.1(2)$ & $3.69(1)$ & $0.020(1)$ & $14(2)$ & $4.02(2)$ & $0.024(5)$ \\
\hline $\mathrm{Sm}$ & 0.205 & $3.3(2)$ & $2.98(1)$ & $0.012(2)$ & $6.7(2)$ & $3.28(1)$ & $0.016(2)$ & $7.9(2)$ & $3.67(1)$ & $0.026(1)$ & $10(1)$ & $4.05(2)$ & $0.021(3)$ \\
\hline Gd & 0.232 & $3.2(2)$ & $2.99(1)$ & $0.010(2)$ & $6.3(2)$ & $3.28(3)$ & $0.015(4)$ & $8.0(1)$ & $3.64(1)$ & $0.023(1)$ & $11(1)$ & $4.02(1)$ & $0.024(4)$ \\
\hline $\mathrm{Tb}$ & 0.263 & $3.4(2)$ & $3.00(1)$ & $0.006(2)$ & $6.7(4)$ & $3.25(2)$ & $0.012(4)$ & $7.5(1)$ & $3.64(1)$ & $0.027(1)$ & $11(1)$ & $4.02(2)$ & $0.019(1)$ \\
\hline $\mathrm{Er}$ & 0.239 & $3.7(2)$ & $2.97(1)$ & $0.006(2)$ & $6.6(5)$ & $3.26(1)$ & $0.012(3)$ & $8.3(2)$ & $3.57(1)$ & $0.025(1)$ & $11(1)$ & $3.95(2)$ & $0.025(5)$ \\
\hline
\end{tabular}

\begin{tabular}{|c|c|c|c|c|c|}
\hline \multirow[b]{2}{*}{$\mathrm{RE}$} & \multirow[b]{2}{*}{ Composition } & \multicolumn{3}{|l|}{$\mathrm{Al}-\mathrm{O}$} & \multirow[b]{2}{*}{$\mathrm{Al}_{2} \mathrm{O}_{3}$ fraction (\%) } \\
\hline & & $N$ & $R$ & $\sigma^{2}$ & \\
\hline $\mathrm{La}$ & 0.225 & $8.0(8)$ & $1.87(2)$ & $0.001(1)$ & 2 \\
\hline $\mathrm{Ce}$ & 0.197 & $6.6(4)$ & $1.92(1)$ & $0.001(1)$ & 2 \\
\hline $\operatorname{Pr}$ & 0.239 & $6.4(7)$ & $1.94(2)$ & $0.001(2)$ & 2 \\
\hline $\mathrm{Sm}$ & 0.169 & $6.4(5)$ & $1.95(2)$ & $0.001(2)$ & 2 \\
\hline $\mathrm{Sm}$ & 0.205 & $13.3(5)$ & $1.93(1)$ & $0.002(1)$ & 2 \\
\hline Gd & 0.232 & $7.8(5)$ & $1.94(2)$ & $0.001(2)$ & 2 \\
\hline $\mathrm{Tb}$ & 0.236 & $7.0(8)$ & $1.93(2)$ & $0.001(1)$ & 2 \\
\hline $\mathrm{Er}$ & 0.239 & $5.5(9)$ & $1.96(4)$ & $0.001(2)$ & 2 \\
\hline
\end{tabular}

co-doped rare-earth phosphate glasses was expected since the extent of doping is less pronounced in the ( $\mathrm{La}, \mathrm{Nd}$ ) case, relative to that of (Ce, Er): both in terms of the substantially lower Nd doping concentration, and the smaller difference in atomic number, $Z$, (and thus ionic size) between La and $\mathrm{Nd}(\Delta Z=3)$ compared with Ce and $\operatorname{Er}(\Delta Z=10)$.

\section{Practical implications of structural invariance to rare-earth co-doping}

The structural invariance to rare-earth co-doping in these phosphate glasses is an important finding since it means that one can tailor the rare-earth doping levels in these materials in order to optimize their optoelectronic properties, which are so sensitive to doping specifications, while bearing no concern for structural complications. Such molecular engineering is therefore 'made easy' by the high structural tolerance of the rareearth phosphate network to doping effects.

The structural resilience of the phosphate network also makes the modelling of these materials simple since one can simply map the local structure of the single rare-earth phosphate glasses onto those of any co-doped analogue, by simple substitution of the appropriate rare-earths according to composition.
While the focus of this paper is on the structural control of these glasses in relation to their optoelectronic applications, it is worth noting that these structural findings also present other, very attractive, prospects for application in the field of nuclear waste storage. The herein observed structural invariance to the incorporation of heavy metals into rare-earth phosphate glasses indicates that the doping of heavier elements, such as uranium or plutonium, into these glasses could be possible without structural compromise. When taken together with the modelling simplicity of these particular glasses owing to this structural invariance, the large open framework and rigid nature of this phosphate network, and the high chemical inertness and thermal stability of these lanthanide phosphate glasses, the possibilities for such heavy-metal containment become even more exciting.

Investigation into different types of nuclear waste host materials (known as 'forms') has been ongoing for nearly 60 years. $^{41}$ The most extensively studied forms are borosilicate glasses, lanthanide silicate glasses, and iron phosphate glasses. ${ }^{41-47}$ These forms must be able to demonstrate a considerable range of necessary properties: incorporation of large amounts of waste loading, easy fabrication, stability in the presence of high levels of radiation, the ability to accommodate 
a mix of contaminants with minimum structural change, resistance to aqueous dissolution over geologic time periods, and the prevention of criticality by either lower concentrations of waste material, or the incorporation of neutron poisons such as Gd and Hf. ${ }^{42}$ Given the relationship of these practical requirements to the subject findings on rare-earth phosphate glasses, this alternative avenue of enquiry will be the subject of future work.

\section{Impact of data resolution from low- and high-energy X-ray diffraction data}

One of the key factors that has enabled this study lies in the resolution and quality of the high-energy X-ray diffraction data that was obtained from the ID15 beamline at the ESRF. In order to illustrate the salient data quality features affecting this study from a technical perspective, the ESRF data is compared with analogous data collected at a lower-energy X-ray synchrotron, the SRS. Summaries of pairwise correlations modelled from the high- and low-energy X-ray diffraction data of a series of (Ce, Er) co-doped rare-earth phosphate glasses are presented in Tables 2 and 3, respectively; corresponding $i(Q)$ plots are given in Fig. 2a and b. For reference to co-doping effects, analogous results from high-energy X-ray diffraction data on a series of single (non-co-doped) rare-earth phosphate glasses are also presented in Table 5; Fig. 5 and 6 display the corresponding $i(Q)$ and $t(r)$ profiles; in this case, comparative SRS data can be compared with previous results. ${ }^{14}$

A comparison of Fig. 2a and b makes it immediately obvious that the intrinsic data quality of the ESRF data is superior. In particular, the signal-to-noise levels in the SRS data are troublesome throughout the data signature, but especially beyond about $6 \AA^{-1}$. The ESRF data are normalized from a much more intense X-ray source. A usable $Q_{\max }$ attainable from the ESRF data also exceeds that of the SRS data, $c f . Q_{\max }=28 \AA^{-1}$ (ESRF) versus $Q_{\max }=22.5 \AA^{-1}$ (SRS); the intrinsic real-space resolution, $\Delta r$, is correspondingly affected given that $\Delta r \approx 2 \pi / Q_{\max }$. A similar trend is realised for the single rare-earth phosphate glass data in all of these respects. Some minor differences in the relative $i(Q)$ intensities are apparent between SRS and ESRF data acquired on the same sample; the significant differences in instrumental resolution could readily afford this ostensible discrepancy in $i(Q) .{ }^{48}$ These technical comparisons of course present no real surprise: a newer-generation synchrotron with higher-energy X-ray radiation will naturally afford better data. However, the scientific consequences of this for the analysis of these rare-earth phosphate glasses are significant.

The first thing to notice is that this ESRF study was able to distinguish between bridging $(\mathrm{P}-\mathrm{O})$ and terminal $(\mathrm{P}=\mathrm{O})$ phosphate bonds. Indeed, none of our previous X-ray diffraction studies have been able to make this distinction; only our previous neutron diffraction study ${ }^{13}$ was able to resolve such bond types owing to the much higher $Q_{\max }$ value $\left(50 \AA^{-1}\right)$ that can be achieved with this type of atomic probe at a high-flux spallation source. Given that structural invariance in the rareearth doped glasses lies at the heart of the discussion in this paper, being able to resolve the $\mathrm{P}-\mathrm{O}$ correlations to this level of fine detail was important in confirming structural invariance of the phosphate network to rare-earth doping effects.

Fig. $2 \mathrm{a}$ and $\mathrm{b}$ show that one can distinguish between the $\mathrm{R}-\mathrm{O}$ correlations in the modelling of two co-existing rare-earths in these glasses. However, the poorer quality of the SRS data did not permit the modelling of the Al-O correlation that lies adjacent to the Er-O correlation, and the $t(r)$ signatures from these two correlations overlap. Consequently, the modelled parameters for the Er-O correlation are compromised in the SRS data (with the exception of the one composition, $x=0.111$ for Er, where it was possible to model the Al-O correlation) as evidenced by a comparison of Tables 2 and 3: the $R_{\text {Ero }}$ separations in the SRS data show a slight, but consistent, shortening relative to the analogous ESRF values, while the corresponding

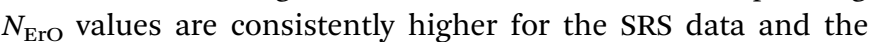

$\sigma_{\text {ErO }}{ }^{2}$ values are also broadly larger in the SRS data, i.e. the peak standard deviation increases. This trend is wholly consistent with the expected trend where the Er-O correlation is 'absorbing' some of the $t(r)$ signal that belongs to the Al-O correlation. This trend is also corroborated by the observation that the smallest discrepancy in $R_{\text {ErO }}, N_{\text {ErO }}$ and $\sigma_{\text {ErO }}{ }^{2}$ values between ESRF and SRS data are for the two (Ce, Er) data sets where $x=0.111$; there, it was possible to model the $\mathrm{Al}-\mathrm{O}$ correlation in both cases.

Conversely, the Ce-O correlation does not appear to be affected between (Ce, Er) SRS and ESRF data, except perhaps for a marginal increase in $\sigma_{\mathrm{CeO}}{ }^{2}$. This stands to reason, in part because the $\mathrm{Ce}-\mathrm{O}$ correlation is much more intense than that for $\mathrm{Er}-\mathrm{O}$ and in part because its intrinsic $R_{\mathrm{CeO}}$ separation is larger such that all correlations in the $t(r)$ vicinity are all modelled. Concerning other correlations that involve a rareearth, no judgment could be made in the same fashion as for $\mathrm{R}-\mathrm{O}$, owing to their larger uncertainties, due to the increased number of overlapping correlations at greater atomic separation, $r$.

In general, a compromise in accuracy is observed in the Er-O correlation parameters for the SRS data when attempting to model the co-doped rare-earth phosphate glasses compared with the analogous modelling of its single rare-earth phosphate glass. Such a compromise is not apparent in the corresponding ESRF data. This demonstrates that the Er-O correlations from co-doped rare-earth phosphate glasses are significantly more reliable than those obtained from SRS data.

Otherwise, refined pairwise correlation parameters and their associated errors are broadly similar between ESRF and SRS generated (Ce, Er) phosphate glass data except for the coordination numbers which are markedly larger for the SRS data. The same comparison for single rare-earth phosphate glass samples (Table 5 versus those obtained by Cole et al. ${ }^{14}$ ) reveals similar findings.

\section{Concluding remarks}

This study presents the first structural evidence of rare-earth co-doping effects in rare-earth phosphate glasses with compositions between those of metaphosphate and ultraphosphate. 
The stark structural invariance as a function of doping levels that is revealed is noteworthy for its practical implications. Specifically, one can tune the optoelectronic properties of these materials by rare-earth co-doping without recourse to any changes in their overall atomic-scale structure. Results also offer great simplicity in modelling levels of rare-earth substitution. Given these and other salient, previously known, attributes of the glasses, they appear to be very attractive to an application beyond optoelectronics: to nuclear waste storage via their ability to encapsulate heavy rare-earth ions without structural compromise. Further investigation into this avenue of application for rare-earth phosphate glasses will be the subject of future work on these materials.

Finally, the technical merits of high-energy diffraction data and the consequentially attainable wide dynamic range data from a high flux source are propounded and are related to their scientific impact on this family of glasses. In particular, these technical merits are shown to enhance the quality of the scientific findings from this study, which is a case where high real-space distinction in atomic pairwise correlations is paramount. The confidence that one can ascribe to the conclusions drawn is thus increased significantly via the use of high-energy diffraction data.

\section{Acknowledgements}

The authors would like to thank the European Synchrotron Radiation Facility, Grenoble, France, and the Synchrotron Radiation Source, Daresbury, UK, for access to Central Facility beamtime. AJC is grateful for the Pam and John Little Overseas Scholarship from UNB. JMC is indebted to an NSERC Discovery grant (355708), the Royal Society for a University Research Fellowship and UNB for the Vice-Chancellor's Research Chair.

\section{Notes and References}

1 M. M. Broer, A. J. Bruce and W. H. Grodkiewicz, Phys. Rev. B: Condens. Matter Mater. Phys., 1992, 45, 7077.

2 G. Carini, G. D’Angelo, G. Tripodo, A. Fontana, F. Rossi and G. A. Saunders, Europhys. Lett., 1997, 40, 435.

3 F. M. Durville, E. G. Behrens and R. C. Powell, Phys. Rev. B: Condens. Matter Mater. Phys., 1986, 34, 4213.

4 D. B. He, C. L. Yu, J. M. Cheng, S. G. Li and L. L. Hu, Chin. Phys. Lett., 2010, 27, 114208.

5 X. Liang, Z. Chaofeng, Y. Yang, S. Yuan and G. Chen, J. Lumin., 2008, 128, 1162.

6 G. A. Saunders, T. Brennan, M. Acet, M. Cankurtaran, H. B. Senin, H. A. A. Sidek and M. Federico, J. Non-Cryst. Solids, 2001, 282, 291.

7 L. Zhang, H. Hu, C. Qi and F. Lin, Opt. Mater., 2001, 17, 371.

8 K. H. Fong, K. Kikuchi, C. S. Goh, S. Y. Set, R. Grange, M. Haiml, A. Schlatter and U. Keller, Opt. Lett., 2007, 32, 38.

9 P. Laporta, S. Taccheo, S. Longhi, O. Svelto and G. Sacchi, Opt. Lett., 1993, 18, 1232.

10 R. A. Martin and J. C. Knight, IEEE Photonics Technol. Lett., 2006, 18, 574 .
11 U. Hoppe, E. Metwalli, R. K. Brow and J. Neuefeind, J. Non-Cryst. Solids, 2002, 297, 263.

12 U. Hoppe, N. P. Wyckoff, R. K. Brow and U. Rütt, J. Non-Cryst. Solids, 2011, 357, 2516.

13 J. M. Cole, E. R. H. van Eck, G. Mountjoy, R. J. Newport, T. Brennan and G. A. Saunders, J. Phys.: Condens. Matter, 1999, 11, 9165.

14 J. M. Cole, E. R. H. van Eck, G. Mountjoy, R. Anderson, T. Brennan, G. Bushnell-Wye, R. J. Newport and G. A. Saunders, J. Phys.: Condens. Matter, 2001, 13, 4105.

15 J. M. Cole, R. J. Newport, D. T. Bowron, R. F. Pettifer, G. Mountjoy, T. Brennan and G. A. Saunders, J. Phys.: Condens. Matter, 2001, 13, 6659.

16 U. Hoppe, R. K. Brow, D. Ilieva, P. Jóvári and A. C. Hannon, J. Non-Cryst. Solids, 2005, 351, 3179.

17 R. Anderson, T. Brennan, G. Mountjoy, R. J. Newport and G. A. Saunders, J. Non-Cryst. Solids, 1998, 232-234, 286.

18 U. Hoppe, R. Kranold, D. Stachel, A. Barz and A. C. Hannon, J. Non-Cryst. Solids, 1998, 232-234, 44.

19 R. Anderson, T. Brennan, J. M. Cole, G. Mountjoy, D. M. Pickup, R. J. Newport and G. A. Saunders, J. Mater. Res., 1999, 14, 4706.

20 D. T. Bowron, R. J. Newport, B. D. Rainford, G. A. Saunders and H. B. Senin, Phys. Rev. B: Condens. Matter Mater. Phys., 1995, 51, 5739.

21 D. T. Bowron, G. Bushnell-Wye, R. J. Newport, B. D. Rainford and G. A. Saunders, J. Phys.: Condens. Matter, 1996, 8, 3337.

22 R. A. Martin, P. S. Salmon, C. J. Benmore, H. E. Fischer and G. J. Cuello, Phys. Rev. B: Condens. Matter Mater. Phys., 2003, 68, 054203.

23 R. A. Martin, P. S. Salmon, H. E. Fischer and G. J. Cuello, Phys. Rev. Lett., 2003, 90, 185501.

24 R. A. Martin, P. S. Salmon, H. E. Fischer and G. J. Cuello, J. Non-Cryst. Solids, 2004, 345 \& 346, 208.

25 G. Mountjoy, J. M. Cole, T. Brennan, R. J. Newport, G. A. Saunders and G. W. Wallidge, J. Non-Cryst. Solids, 2001, 279, 20.

26 G. Mountjoy, R. Anderson, D. T. Bowron and R. J. Newport, J. Non-Cryst. Solids, 1998, 232-234, 227.

27 J. M. Cole, A. C. Wright, R. J. Newport, R. N. Sinclair, H. E. Fischer, G. J. Cuello and R. A. Martin, J. Phys.: Condens. Matter, 2007, 19, 056002.

28 J. M. Cole, A. C. Hannon, R. A. Martin and R. J. Newport, Phys. Rev. B: Condens. Matter Mater. Phys., 2006, 73, 14210.

29 A. Mierzejewski, G. A. Saunders, H. A. A. Sidek and B. Bridge, J. Non-Cryst. Solids, 1988, 104, 323.

30 T. Brennan, PhD thesis, University of Bath, UK, 1998.

31 B. E. Warren, X-ray Diffraction, Addison-Wesley Publishing Company, London, 1969.

32 D. T. Cromer, J. Chem. Phys., 1969, 50, 4857.

33 D. T. Cromer and J. B. Mann, J. Chem. Phys., 1967, 47, 1892.

34 D. T. Cromer and J. B. Mann, Acta Crystallogr., Sect. A: Cryst. Phys., Diffr., Theor. Gen. Cryst., 1968, 24, 321.

35 P. H. Gaskell, Models for the Structure of Amorphous Solids, in Materials Science and Technology A Comprehensive Treatment Volume 9: Glasses and Amorphous Materials, 
ed. R. W. Haasen, P. Kramer, E. J. Cahn and J. Zarzycki, VCH, Cambridge, 1991, pp. 175-278.

36 P. Harmann, J. Vogel and B. Schnabel, J. Non-Cryst. Solids, 1994, 176, 157-163.

37 E. R. H. van Eck, A. P. M. Kentgens, H. Kraus and R. Prins, J. Phys. Chem., 1995, 99, 16080-16086.

38 R. K. Brow, R. J. Kirkpatrick and G. L. Turner, J. Am. Ceram. Soc., 1993, 76, 919-928.

39 R. Dupree, I. Farnan, A. J. Forty, S. El-Mashri and L. Bottyan, J. Phys., Colloq., 1985, 46, C8-113-C8-117.

40 R. A. Martin, P. S. Salmon, D. C. Carroll, M. E. Smith and A. C. Hannon, J. Phys.: Condens. Matter, 2008, 20, 115204.

41 L. P. Hatch, Am. Sci., 1953, 41, 410.

42 R. C. Ewing and W. J. Weber, Actinide Waste Forms and Radiation Effects, in The Chemistry of the Actinide and
Transactinide Element, ed. L. R. Morss, N. M. Edelstein and J. Fuger, Springer, Dordrecht, 2011, ch. 35, vol. 6, pp. 3813-3887.

43 M. T. Harrison, C. S. Scales, P. A. Bingham and R. J. Hand, Mater. Res. Soc. Symp. Proc., 2007, 985, 151-156.

44 C. L. Crawford, J. C. Marra and N. E. Bibler, J. Alloys Compd., 2007, 444-445, 569.

45 J. M. Schofield, P. A. Bingham and R. J. Hand, Mater. Res. Soc. Symp. Proc., 2008, 1107, 253.

46 P. A. Bingham, R. J. Hand, O. M. Hannant, S. D. Forder and S. H. Kilcoyne, J. Non-Cryst. Solids, 2009, 355, 1526-1538.

47 P. A. Bingham and R. J. Hand, Mater. Res. Bull., 2008, 43, 1679-1693.

48 X. Qiu, E. S. BozÏin, P. Juhas, T. Proffen and S. J. L. Billinge, J. Appl. Crystallogr., 2004, 37, 110-116. 